\title{
Yugos cornales de Castilla y León. Estudio tipológico ${ }^{1}$
}

\author{
ARTURO MARTín CRIADO \\ I.E.S. "Leopoldo Cano". Valladolid
}

\section{RESUMEN}

Los yugos con que se unce el ganado vacuno de labor son aperos muy antiguos e imprescindibles en la agricultura tradicional. En Castilla y León, como en la mayor parte de la Península Ibérica, se emplea el yugo cornal, que presenta una rica tipología geográfica, con variantes funcionales dentro de cada tipo.

Palabras clave: Agricultura, Aperos, Yugos, Tipología, Castilla y León.

\section{SUMMARY}

The yokes for the cattle used in farming (cows and oxen) are ancient yet essential implements for traditional agriculture. In the region of Castille-Leon, as in most other areas in the Iberian Peninsula, farmers use a kind of yoke which is tied to the horns of the animals. This kind of yoke presents a rich variety of local types, and functional variants within these types, as a result of its wide geographical distribution.

Key words: Agriculture, Farming Implements, Yokes, Typology, Region of Castille-Leon.

Desde que el ganado vacuno fue domesticado y empleado para la labranza y el transporte, se precisó de un útil, que podía ir colocado en el cuello o en la cornamenta, para aprovechar la fuerza del animal. En el primer caso, tenemos el yugo yugular, también denominado yugal o de cruz, que es un madero colocado sobre la cerviz y atado al cuello. Pare-

${ }^{1}$ Este trabajo ha crecido sobre cimientos viajeros; la idea originaria surgió en Canarias y fue desarrollándose al ritmo de numerosos viajes a distintos lugares. En todos encontré personas que me ayudaron; a ellas mi profundo agradecimiento, en especial a Carlos Piñel, $M^{a}$ Teresa Sánchez Trujillano, José Ramón Gómez Martínez, Carlos Ezquerro, M. ${ }^{a}$ Ángeles Martín. Y a Raquel, que me acompañó siempre.

RDTP, LVII, 2 (2002): 41-78 
ce el más antiguo y el más extendido por el mundo, pues se usa en África, Asia y, en Europa, en los países eslavos, Italia, Irlanda y algunas zonas de la Península Ibérica (Aranzadi 1931: 335), como después se verá. En el segundo, el yugo cornal o frontal, el madero es colocado sobre la nuca o testuz del animal, tocando la parte posterior de los cuernos, a los que se ata, así como a la frente. Se utiliza en un área muy reducida de Europa Occidental: Francia, Bélgica, Austria, Suiza y zona central de la Península Ibérica. En ésta última, el yugo cornal se ha empleado en Asturias, Cantabria, Castilla y León, País Vasco, La Rioja, Navarra, Aragón, salvo algunas zonas del Pirineo, Extremadura, Madrid y Castilla-La Mancha, Valencia, Murcia y Andalucía. Desde aquí pasó a las Islas Canarias y América.

El yugo yugular ha sido tradicional, en el oriente peninsular, en unos cuantos valles pirenaicos aragoneses y en Cataluña. En el valle oscense de Chistau, el más usado ha sido el chugo de canaulas, es decir, de collares, pero en el siglo $\mathrm{xx}$ se introdujo un tipo de yugo cornal, chugo de toza, similar al que se emplea en otras zonas de Aragón (Ortega, Lasaosa y Sarasa 1999: 72-74). En Gistaín e Isábena también es de collares, mientras que en el Cinca y Esera es de estacas (Violant y Simorra 1947: 460). En Cataluña, el yugo propio de la tierra ha sido el jou de coll, yugular, por lo general de collares, aunque también aparece el de estacas en algunos lugares; en época moderna y por influencia francesa, se ha ido introduciendo el jou de cap, cornal, en comarcas como Pallars, Tremp, Ribagorza, Valle de Arán, etc. (Violant y Simorra 1958).

En el occidente peninsular, los yugulares se han empleado en Galicia, excepto en la mitad sudoriental de la provincia de Lugo y en casi toda la de Orense donde se han utilizado yugos cornales, y en todo Portugal, salvo algunas zonas de Tras os Montes (Krüger 1947: 12). Los yugos yugulares gallegos, cangas (Liste Fernández 1997: 170), son, como los catalanes y aragoneses, de collares y de estacas; el xugo de mulida (ibid.) o castellano (González Pérez 1997: 75) es de tipo cornal, predominando una hechura muy recta, con camellas de curva poco pronunciada que tiene parecido con los castellanos de Soria y Segovia y con los aragoneses (Liste Fernández 1997: 171), si bien hay otros más ligeros, de camella muy curva, que también se usan en el Bierzo; de ambos trataré más adelante.

La denominación de este útil en toda la España románica se hace con términos derivados del latín IUGUM, cuya evolución, no muy bien explicada (Corominas y Pascual 1991; Ariza Viguera 1988: 126; Martín Criado 1999), dio lugar a muchas variantes dialectales: ubio es la voz castellana popular usada en la zona central desde Burgos y Palencia hasta Andalucía oriental, pasando por Soria, Segovia y La Mancha; yubo y yubio aparecen al oriente de Burgos, Soria, La Rioja, algo en Aragón, Cuenca y 
Murcia; xubo y yugo se usan en Navarra y Aragón, donde también es muy frecuente chugo. En Cataluña, el yugo cornal, de introducción moderna, se denomina jou de cap. En Cantabria, Palencia y la comarca leonesa de Sajambre se llama ugo, así como ugu en el oriente asturiano; en León y Zamora predomina yugo, si bien en la zona occidental se dice xugo, como en Galicia, y xugu en Babia y Laciana, al igual que en Asturias occidental; en Cabrera y Aliste, jugo y jubo. Más al sur, en Valladolid, Ávila, Salamanca, Extremadura y Andalucía Occidental se emplea yugo; en algunas zonas salmantinas y extremeñas, también ñugo. Como estas denominaciones no coinciden necesariamente con los tipos de yugos, de ahora en adelante prescindiré de ellas y emplearé el término del castellano culto yugo, salvo en algún caso muy puntual en que considere oportuno citar el vocablo local.

Los yugos de tipo yugular son, por lo que sabemos hoy en día, muy antiguos. En Mesopotamia ya eran habituales. Este mismo tipo de yugo parece ser el usado en Grecia. También en Italia se empleó esta misma clase de yugo, pero no en todo el Imperio Romano. El propio Columela, aunque recomienda uncir los bueyes por el cuello, reconoce que en algunas provincias se uncen por los cuernos:

que el yugo se asiente mejor sobre las cervices. Esta forma de uncir es la más aceptada, pues ligar el yugo a los cuernos, cosa que se hace en algunas provincias, se rechaza por casi todos los que escribieron recomendaciones para los labradores (Columela 1988: 31).

Una de estas provincias debía ser Hispania, según puede deducirse del propio testimonio de Columela, hispano de nacimiento, y de algunos testimonios gráficos que aportan monedas y cerámicas ibéricas. Las monedas de Obulco (Porcuna, Jaén) presentan, en el anverso, el busto de una diosa y, en el reverso, una espiga con un arado dental a un lado y un yugo al otro (Caro Baroja 1983: 570; García-Bellido 1992: 247; Fernández Montes 1992: 268). Los yugos representados en estas monedas han sido considerados por J. Caro Baroja (1983: 107) del mismo tipo o similares a los actuales asturleoneses, si bien en las monedas aparecen importantes variantes y no está claro que todos ellos correspondan a yugos cornales. En una vitrina del Museo de Teruel, podemos contemplar una urna funeraria, procedente de las excavaciones del Cabezo de La Guardia, en Alcorisa, con una escena en la que un labrador empuña la esteva de una arado tirado por bueyes unidos por un yugo que va de los cuernos de uno al morro del otro. En efecto, la escena aporta información clara, tanto sobre el tipo de arado ibérico, que era dental, como sobre el de yugo, que casi con total seguridad era cornal. Resumiendo, a partir de todo esto se pue- 
de afirmar que el tipo de yugo empleado en la España ibérica y romana era cornal, lo que ya me parece más arriesgado es establecer relaciones con los tipos actuales de yugos cornales.

En la Alta Edad Media, escasean los testimonios, si bien contamos con algunos documentos que aportan algo de información. En documentos del siglo $\mathrm{X}$, copiados en el cartulario del monasterio burgalés de Cardeña, se nos informa de que asnos y mulos son empleados sobre todo para el transporte a lomo, "mulo aut asyno qui cotidie farina deportant et ligna monasterio", mientras que el carro era arrastrado por un yugo de bueyes, como se muestra al establecer el castigo a quien lleve, de los bosques acotados, un carro de leña cortada sin permiso: "et si karro ibi adprehensum fuerit, mittantur in camino ygnis, et illos bobes sint portati ad monasterion (Serrano 1910: 10). En otros documentos se aportan datos sobre el color y el precio de los bueyes, pero nada sobre el tipo de yugo con que se uncían, a pesar de que a veces se hacen menciones de tipo general: "et II uobes cun toto suo atondo, suo carro et tota sua loramine" (Garrido Garrido 1983: 20). El arte románico, con su gusto por las imágenes anecdóticas, nos saca en parte de esta oscuridad. Las mejores figuras sobre esto en Castilla son dos escenas del calendario esculpido en la portada de la iglesia de Beleña de Sorbe, en Guadalajara; una es de la trilla, que representa el mes de agosto, en la que una yunta de bueyes unidos con yugo cornal arrastra un trillo; la otra, correspondiente al mes de noviembre, es una vista cenital de una pareja de bueyes uncidos a un arado cama con un yugo cornal que apoya en unas mullidas melenas y con las coyundas bien marcadas (Mingote Calderón 1996: 81, 96; Ruiz Montejo 1995: 620-621). Esto mismo confirma algún documento del siglo XIII, como el contrato por el que el monasterio burgalés de Las Huelgas arrienda la casa de Valdeparada a Fernando Tobero por tres años, cediéndole, además de las tierras, ganado y aperos:

Et sin esto, dexamosuos III yuuos de bues, preciados en XLII maravedis, e I carro maderiço, apreçiado en I maravedi, e III trillos con sos tamiços, en XII sueldos, e I yuuo carral con so sueo (sic) en V sueldos, e I asno apreciado en IIII maravedis minus tercia [...] e III aradros con sus reias en VI sueldos, e III yuuos con sus melenas e con sus coyundas, en VI sueldos (Lizoain Garrido 1985: 346)

En él se habla claramente de yugos cornales por ser los únicos que se emplean con la melena y las coyundas; además se distingue entre yugos de carro, carral, que se ataba al carro con el sobeo (sueo) y el resto, que serían de arar. Lo mismo se documenta en Segovia a finales del siglo XIII (Mingote Calderón 1997: 236-241). El arte gótico, sobre todo el más popularizante, aporta escenas en las que aparecen bueyes trabajando un- 
cidos por yugo cornal, como en alguna miniatura de las Cantigas de Santa María de Alfonso X y en un conocido capitel del claustro de Sta. María la Real de Nieva. También en algunas tablas góticas y renacentistas que representan la traslación del cuerpo de Santiago, que viaja sobre una carreta, se percibe el yugo así como melenas y coyundas. Entre ellas se puede citar la del retablo mayor de la Catedral de León, de Nicolás Francés, o, ya en la primera mitad del siglo XVI, la del maestro de Astorga, del Museo Lázaro Galdiano, que muestra una vista posterior de un yugo leonés idéntico a los actuales.

Por otro lado, en el período de los Reyes Católicos, tanto en obras reales, como en otras de iniciativa privada, se repite la imagen del escudo real, con una clara intencionalidad política y simbólica del poder (Mingote Calderón e. p.), donde, el yugo y las flechas, divisa de ambos monarcas, sirven de nexo a la heráldica tradicional de ambas coronas (Yarza Luaces 1993: 70). El yugo aparece por vez primera individualizado y a gran tamaño; el artista, que en las escenas de género antes citadas, lo trataba de manera esquemática, ahora lo dibuja o lo esculpe con bastante detalle y nos da un repertorio que parece inspirado en la realidad. Un primer tipo es el yugo de tres camellas, de los que presento una muestra escogida al azar en la figura 1; no deja de ser sorprendente la
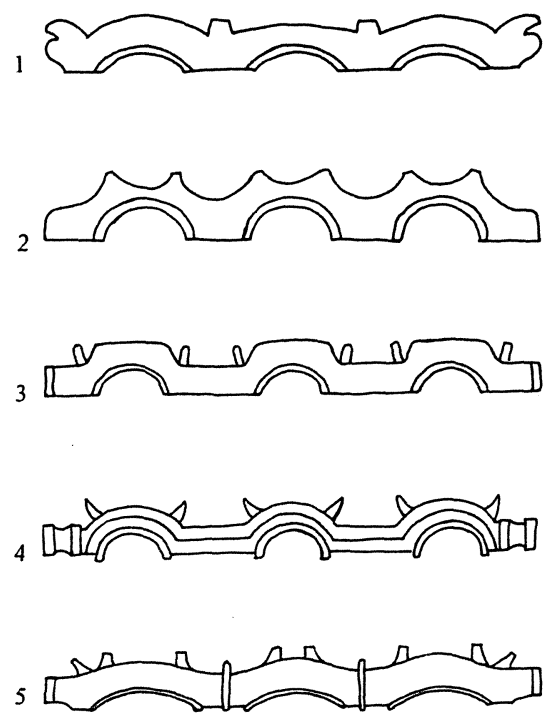

Figura 1.-Yugos de tres camellas que figuran en los escudos de los Reyes Católicos de: 1. Puerta del Alcázar de Ávila; 2. Casa de las Conchas de Salamanca; 3. Posada de la Hermandad de Toledo; 4. Fachada de la Universidad de Salamanca; 5. Portada de la iglesia de Santa María en Aranda de Duero. 
frecuencia con que aparece y la gran semejanza que guarda con los yugos de doma estudiados por J. L. Mingote Calderón (1992: 3-28); además, contamos con el testimonio, contemporáneo a estas imágenes, de Gabriel Alonso de Herrera que confirma su uso:

Hay algunos [novillos] tan porfiados que o se echan que no quieren andar o por estar muy recios no los puede regir un buey, a estos es bueno hacer un yugo largo en el cual puedan uñir tres bueyes y vaya el que domaren en medio (1970: 339)

En segundo lugar, tenemos yugos de dos camellas de varios tipos. En Valladolid, en las fachadas de la Iglesia de San Pablo y del colegio de San Gregorio, aparecen en alto relieve, con un tono naturalista, unos yugos semejantes a los actuales nororientales o burgaleses (figura 2); sin embargo, el que se repite a lo largo de todo el claustro de San Gregorio es más geométrico, de camellas semicirculares. De principios del siglo XVI es el importante testimonio del escritor, ya citado, G. A. de Herrera, que, frente a Columela, defiende la tradición castellana de uncir a los bueyes por los cuernos:

Cuanto a los bueyes, dice Columella que es mejor uñir los pescuezos que no a la cabeza o a los cuernos, porque con mayor fuerza rompen la tierra, porque con
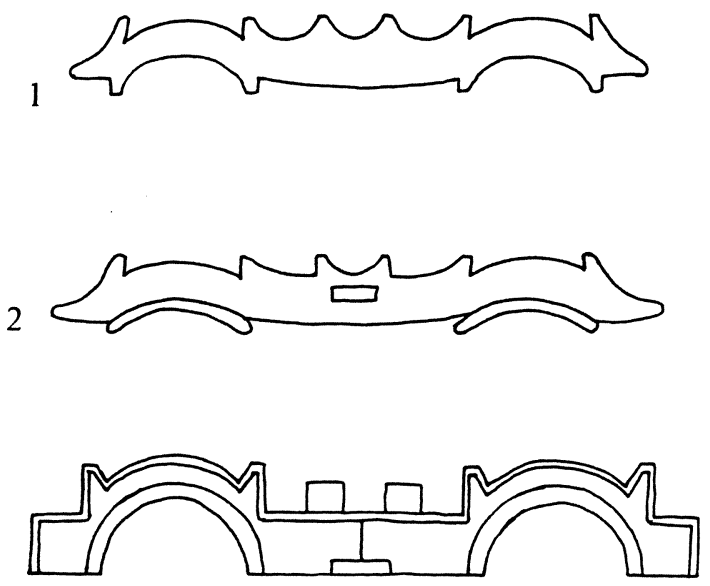

3

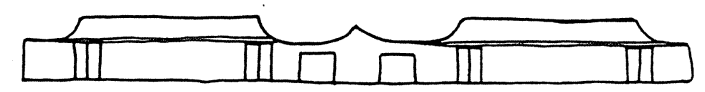

Figura 2.-Yugos de dos camellas de los escudos de los Reyes Católicos de: 1. Fachada de San Gregorio; 2. Fachada de San Pablo; 3. Claustro de San Gregorio; los tres de Valladolid. 
todo el cuerpo traen el arado; mas esto en Italia o Francia, que son los bueyes pequeños y tienen los cuernos menudos y flacos, tiene más lugar de hacerse así que en Castilla, onde hay bueyes bien grandes y que cualquier cargo pueden bien traer con la fuerza de la cabeza y cuernos (1970: 18)

Durante los siglos xvII y xviII, el interés de los artistas por las escenas rurales disminuye y apenas ${ }^{2}$ se encuentran testimonios hasta llegar al XIX, cuando los pintores costumbristas y los fotógrafos nos proporcionan imágenes de escenas de trabajo con los bueyes, en las que se confirma el uso del yugo cornal pero sin poder llegar, por lo general, a mayores precisiones.

\section{TIPOLOGÍA}

El estudio tipológico de todo lo que se ha dado en llamar cultura material es fundamental en la ciencias sociales por estar basado en la comparación, principal instrumento con que cuentan para ir más allá de la mera descripción. Por otro lado, en la etnografía española, esta clase de estudios está, en buena medida, por hacer. A continuación, voy a establecer los tipos de yugo cornal que en el siglo $\mathrm{xx}$ se han empleado en Castilla y León, basándome en la literatura publicada, poca y dispersa, a veces en obras de dialectología cuyo principal objeto de estudio es la lengua y no las cosas, por lo que la información sobre éstas suele ser superficial, y, sobre todo en el estudio directo de las colecciones de instituciones o particulares, o el estudio de campo en lugares representativos de una comarca. Además, cuando me sea posible, relacionaré los tipos empleados en esta comunidad con los de otras.

En la denominación de los distintos tipos, he procurado no caer en el excesivo localismo ni cierto chovinismo que a veces se da en la etnografia; he aceptado algunas denominaciones ya establecidas que me parecen bien fundadas, si bien la mayoría pecan de parciales. El léxico del yugo y de sus partes es totalmente dialectológico, con muy pocos términos aceptados en la lengua culta; para no caer en un galimatías terminológico (Mingote Calderón 1996: 28-29), he unificado las denominaciones de las partes del yugo, independientemente de los tipos y de su localización geográfica, pues, de lo contrario, sería necesario recurrir a una tabla de equivalencias que harían el texto inentendible. Por lo tanto (figura 3), la

\footnotetext{
${ }^{2}$ Un caso excepcional es el de Goya, con su gusto por las escenas populares; suyo es un grabado que muestra una escena de arada, vista desde el lugar del labrador, reproducida en J. Fernández Pérez e I. González Tascón (eds.), Ciencia, técnica y estado en la España ilustrada. Madrid-Zaragoza: Ministerio de Educación y Ciencia. 1990: 69.
} 

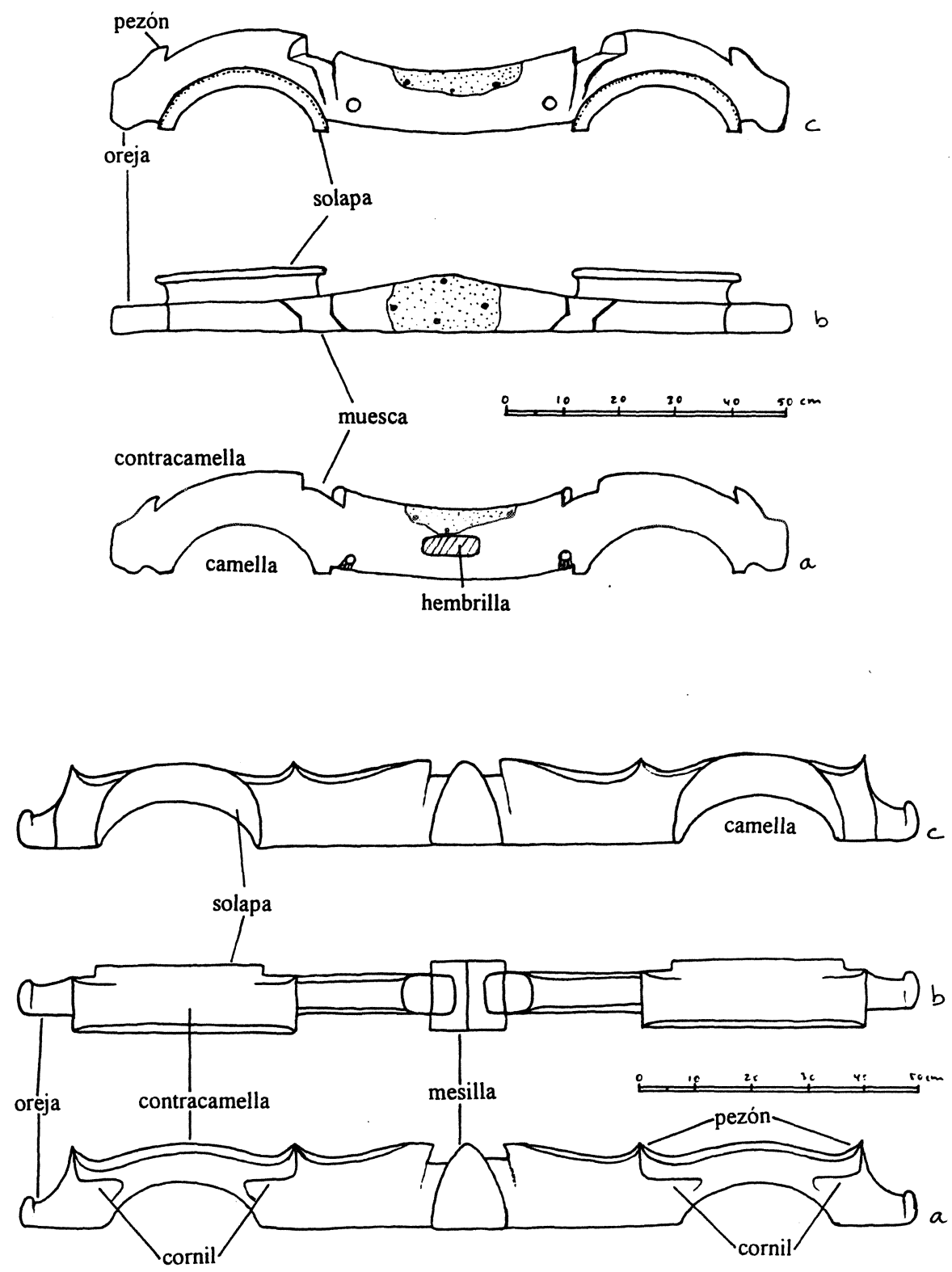

FIGURA 3.-Terminología unificada de las partes del yugo empleada en este trabajo. 
camella es cada uno de los dos vanos más o menos semicirculares que encajan sobre la nuca del animal; la contracamella, la curva superior que hay sobre cada camella; en el centro del yugo carretero hay un ensanchamiento de diferentes formas, la mesilla, mientras que, en los yugos de arar, existe un agujero, la hembrilla, por donde pasan las correas, medianas, que sujetan el barzón; lo extremos laterales son las orejas, y los salientes superiores, los pezones; algunos yugos en la parte superior tienen una muesca, especie de entalladura; la mayoría de los yugos de Castilla y León, salvo muchos de los de tipo leonés, tienen, por la parte posterior de la camella, un saliente, la solapa, que monta sobre el cuello del animal; finalmente, los del tipo que denomino suroccidental presentan en la parte anterior, a los lados de la camella, un saliente entallado que apoya sobre los cuernos, el cornil. En cuanto a la representación gráfica, cada ejemplar aparece con una vista frontal (a), una cenital (b) y una posterior (c); la imagen de cada yugo, salvo unos pocos casos, se forma con estas tres vistas, que se deben "leer" de abajo (desde a) a arriba (hasta c).

\section{Tipo noroccidental}

Dentro de la Comunidad de Castilla y León, se extiende por las provincias de León, Palencia, norte de Valladolid y norte y oeste de Zamora; presenta dos subtipos: leonés y palentino.

\subsection{Yugo leonés}

Este yugo, si realmente es heredero de los yugos ibéricos representados en algunas monedas de Obulco, como algunos autores piensan, representaría la pervivencia de una tradición bimilenaria. Se caracteriza por sus grandes camellas en forma de $\mathrm{U}$ invertida, algo más anchas y bastante más altas que las de los yugos de otros tipos; de ahí que a veces se le haya llamado camellón. A los lados salen dos orejas hacia fuera y una hacia el centro del yugo, y, por lo general, no tiene solapa en la parte posterior de las camellas. En conjunto, es muy alto en comparación con los otros y de formas curvadas, orgánicas.

El yugo de grandes camellas, el prototipo, abunda en especial en las comarcas de la franja central de la provincia de León, desde las tierras montañosas de Babia y Laciana, pasando por la Cepeda y la Maragatería, hasta las tierras del sur de León y norte de Zamora (figura 4). Es muy conocido el yugo maragato dibujado por Aragón Escacena y reproducido 

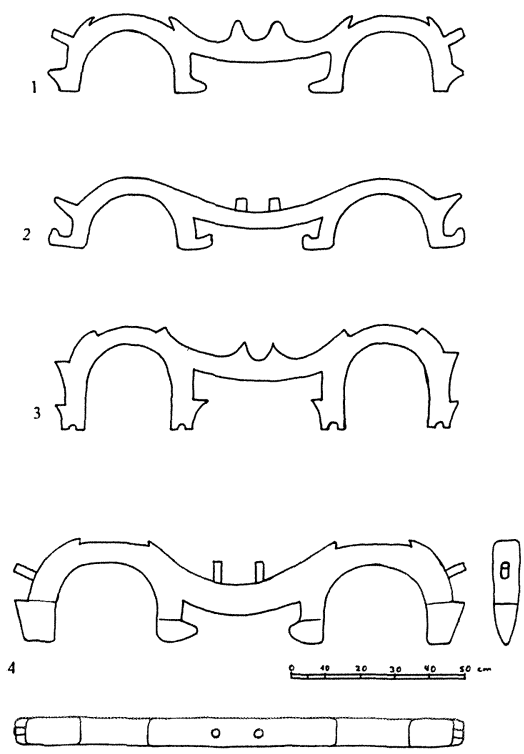

Figura 4.-Yugos de tipo leonés: 1. De Babia y Laciana, según G. Álvarez; 2. De la Cepeda, según A. Álvarez Cabeza y F. J. García Martínez; 3. De la Maragatería, según T. de Aranzadi; 4. De la comarca de Benavente.
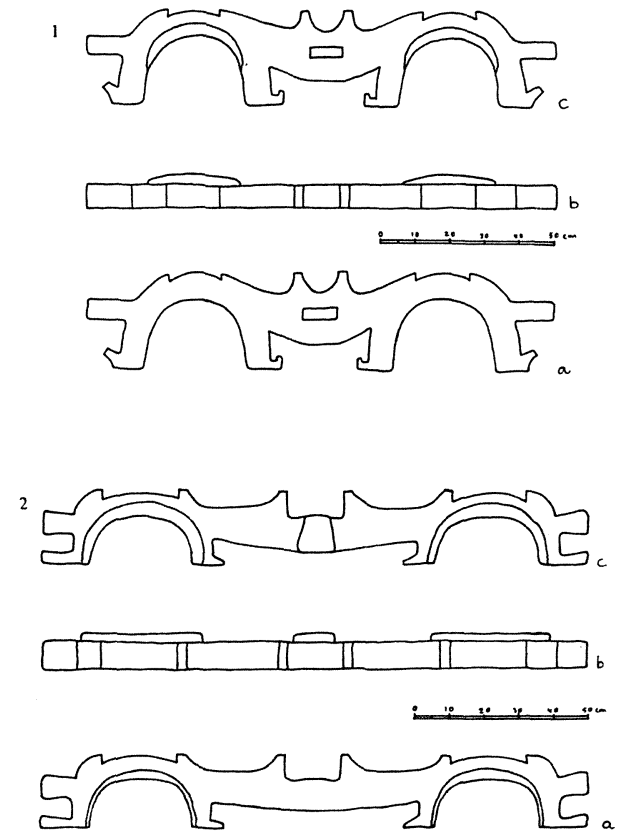

FIGURA 5.-Yugos de tipo leonés, variantes funcionales: 1. Yugo vallisoletano de Tierra de Campos para arar; 2. Yugo carretero de Zamora (Colección Etnográfica de Caja España, Zamora). 
por Aranzadi, de profundas camellas, si bien es más frecuente el yugo procedente de Benavente de la figura anterior, también con grandes camellas, orejas más largas y perfil lateral en forma de cuña.

Estos yugos no suelen tener variantes o subtipos funcionales, pues uno mismo servía tanto para arrastrar el carro como el arado o el trillo; sin embargo, en las áreas más meridionales, sí encontramos alguna variante. De Zamora procede el yugo de la figura 5, más largo de lo habitual y con un pequeño resalte posterior en forma de mesilla para atar al carro; además, presenta unas pequeñas solapas. Esta rareza de las solapas se da también en el otro yugo de la misma figura, de la Tierra de Campos vallisoletana, que tiene hembrilla para atar el barzón, por lo que se empleaba para tirar del arado y del trillo. Otra variante también zamorana es la del yugo mixto de vaca y asno, característico de los pequeños labradores, como el que posee la Colección Etnográfica de Caja España en Zamora.

En las comarcas orientales de la provincia de León, y las asturianas, las camellas no son tan grandes, si bien se mantienen los demás rasgos del tipo. Los yugos de Sajambre (figura 6) son, en general, más bajos y presentan, como los de la vecina Palencia, una variante de yugo con mesilla para el carro. Más al sur, en los Oteros, comarca cerealista y vitivinícola, he visto otra variante funcional, un yugo de 165 centímetros de longitud empleado para arar las viñas (véase figura anterior).

La zona occidental de la provincia leonesa presenta una mayor complejidad. Por un lado, se emplea un yugo de tipo leonés de camellas más pequeñas, como se comprueba en los del Bierzo y la Cabrera (figura 7). Junto a él, aparecen otros con camellas de curvatura media, sin orejas en el centro y una sola en los extremos, de forma redondeada o de cola de milano, como el que, bastante deteriorado y sin procedencia conocida, se conserva en el Museo Etnográfico de León; este tipo se usa en el Bierzo y comarcas limítrofes de Galicia. En los Ancares, junto al yugo de tipo leonés, hay uno de camellas poco curvadas, muy abiertas, que se asemeja bastante a otros del occidente asturiano (figura 8). Estos yugos cornales de comarcas vecinas de Asturias, Galicia y León parecen autóctonos, y, si, por un lado, se diferencian claramente del tipo leonés, por otro, tampoco se identifican con los yugos cornales gallegos de las comarcas interiores, que, formalmente, tienen bastantes rasgos semejantes a los yugos sorianos y segovianos, pues son rectilíneos, con camellas poco curvadas y bastante toscos. En el occidente zamorano, en Aliste y Sayago, aparecen yugos de camellas de tendencia semicircular o semiovaladas, con orejas simples de cola de milano, algunos de ellos con solapa posterior (figura 9) relacionados con los de la Cabrera; entre estos, destaca un yugo de doma de tres camellas (figura 10), variante que no parece ser frecuente 


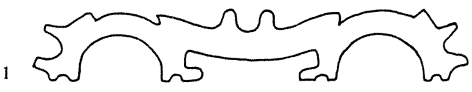
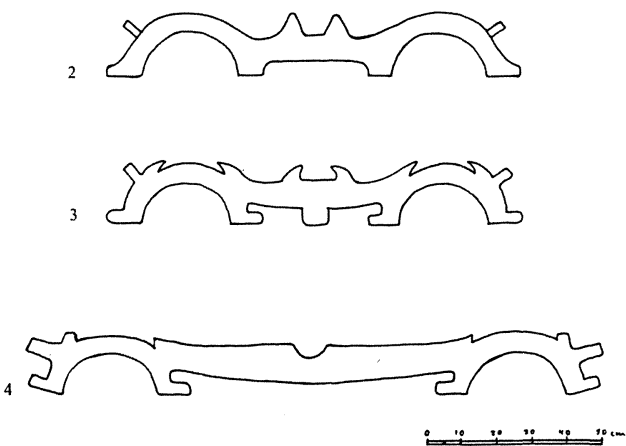

Figura 6.-Yugos leoneses orientales: 1. De Cabrales, en el oriente asturiano, según Álvarez Fernández-Cañedo; 2. y 3. De Oseja de Sajambre, según A. R. Fernández González; 4. Yugo de arar viñas de la comarca de los Oteros, León.

1

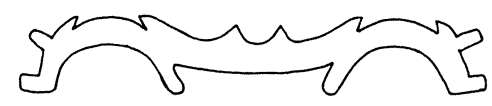

2
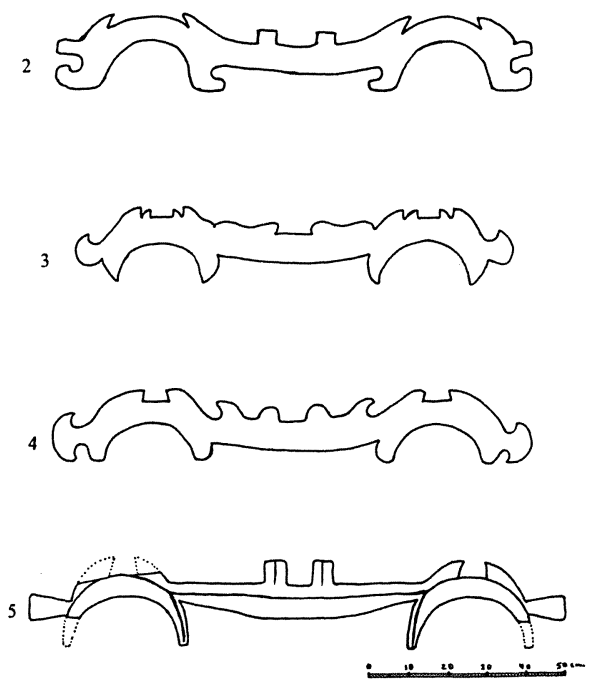

Figura 7.-Yugos del occidente de la provincia de León. De tipo leonés: 1. Del Bierzo, según V. García Rey; 2. De la Cabrera, según C. Casado Lobato. De otro tipo: 3. y 4. De la Cabrera, según Casado Lobato; 5. Del Bierzo y raya de Galicia (Museo Etnográfico de León). 


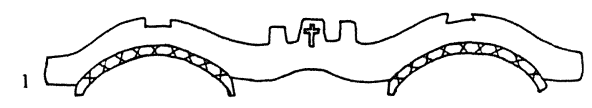

2

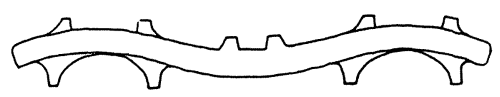

3
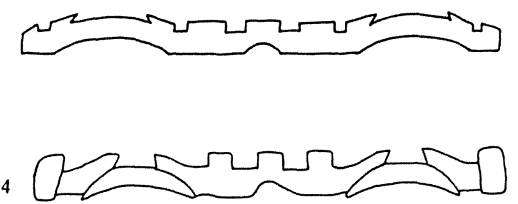

Figura 8.-1. Yugo de Grandas de Salime (Asturias), según A. Graña García y J. Naveiras Escanlar; 2. Yugo de los Ancares, según J. R. Fernández González. Yugos cornales gallegos: 3. Según F. Krüger; 4. Del Museo del Pueblo Gallego.

1
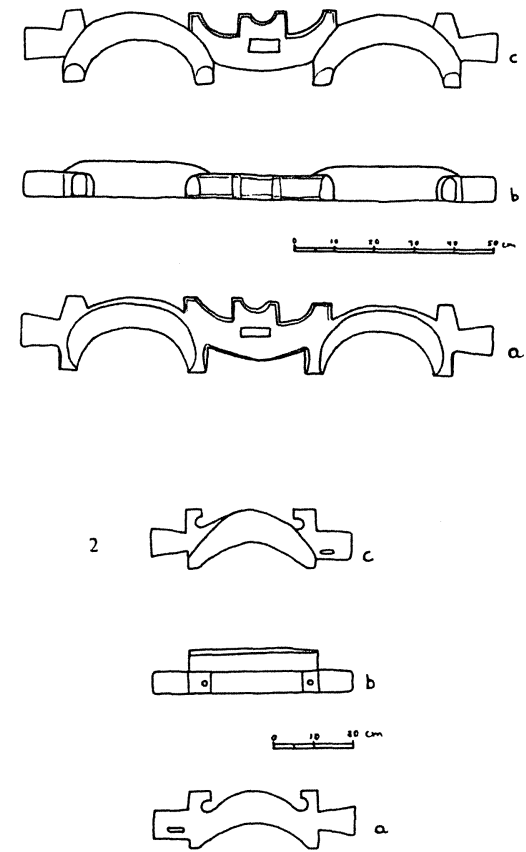

FIGURA 9.-Yugos de las comarcas occidentales zamoranas que conviven con los de tipo leonés (Colección Etnográfica de Caja España, Zamora). 
en la zona, pues, según explica L. A. Sánchez Gómez, el procedimiento para domar los novillos no solía incluir el uso de este yugo (1993: 172).

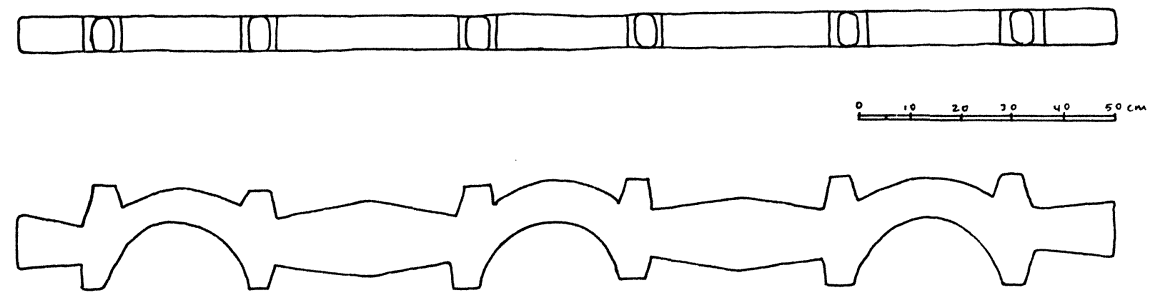

Figura 10.-Yugo de doma de tres camellas del occidente zamorano (Colección Etnográfica de Caja España, Zamora).

\subsection{Yugo palentino}

Este subtipo, conocido también como perniano, aparece en la mitad septentrional de la provincia de Palencia, hasta el Camino de Santiago, ya que al sur de esta línea, en las comarcas de Tierra de Campos y Cerrato, la labranza con bueyes y vacas fue desapareciendo a lo largo del siglo XIX y apenas quedan rastros de yugos cornales autóctonos, pero creo que, al menos por Tierra de Campos, debió de estar extendido el yugo de tipo noroccidental en sus distintas variantes. Con relación al leonés, presenta como rasgos distintivos unas camellas más pequeñas, el tener en la parte posterior una solapa que monta sobre el cuello del animal, si bien en algún ejemplar antiguo no aparece, y la clara diferenciación funcional entre yugo carretero, con mesilla incorporada, y yugo de arar con hembrilla central.

En la montaña se dan formas más ligeras, como se ve en los ejemplares del Museo Etnográfico "Piedad Isla" de Cervera de Pisuerga, quizá porque se utilizaron sobre todo para vacas. En las comarcas de la Vega, Ojeda, Valdavia y zona norte de Tierra de Campos, se han empleado yugos con la misma forma pero suelen ser algo más fuertes, pesados, sobre todo si se usaron con bueyes, como el yugo de Villamorco que publiqué hace unos año (Martín Criado 1995: 187). Este tipo se ha utilizado también en Cantabria; es el que González Echegaray, que rechaza el nombre tradicional de perniano, denomina cántabro B (1971: 142-146). Los yugos carreteros presentan siempre una mesilla alargada, de corte cuadrangular o ligeramente más estrecha por arriba (figura 11), que, unas veces, está labrada 

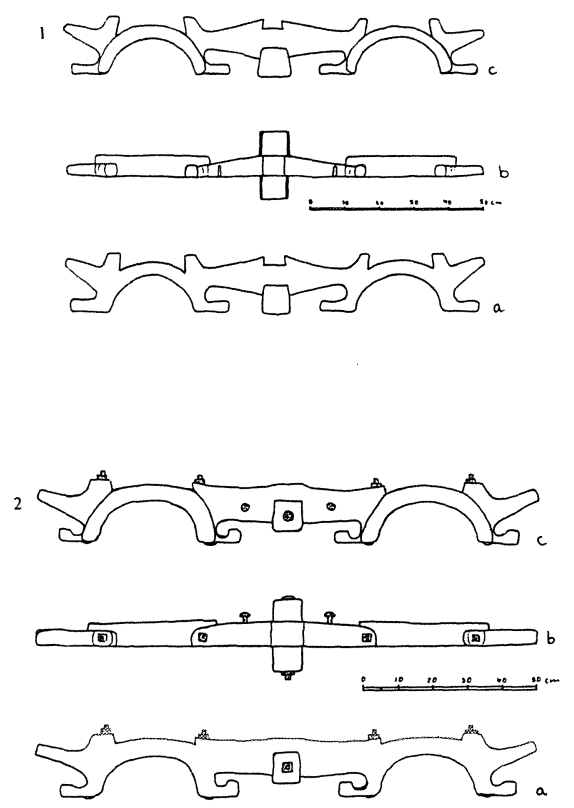

FIgURA 11.-Yugos carreteros de tipo palentino: 1. De Cervera de Pisuerga (Museo Etnográfico Piedad Isla); 2. De Saldaña.
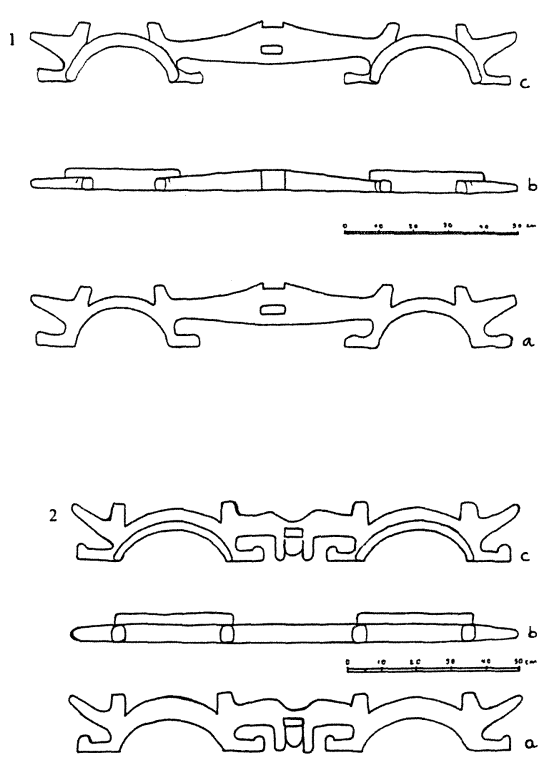

Figura 12.-Yugos de arar de tipo palentino: 1. De Cervera de Pisuerga (Museo Etnográfico Piedad Isla); 2. De Boadilla del Camino. 
en la misma pieza de madera, $y$, otras, es un taco que se une al yugo con un largo tornillo de hierro. Los yugos de arar y trillar (figura 12) se caracterizan por la hembrilla central, y podían ser adaptados al carro por medio de una mesilla que se ataba a la hembrilla, pero casi todos los labradores tenían de ambas clases. Una variante que se da en las comarcas montañosas es el yugo para un solo animal (figura 13), que se ponía a una vaca para arar las huertas o arrastrar un carrillo

Un yugo que tiene cierta seme-

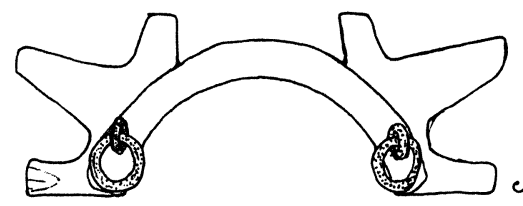
janza con los de tipo palentino se conserva en el Museo de La Rioja de Logroño, si bien sus camellas son muy poco curvadas; es un yugo muy débil, usado para exhibición, para pasear la pareja de vacas.

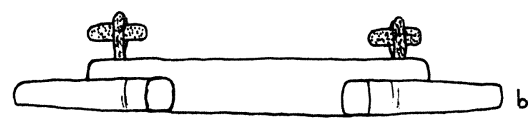

En la montaña oriental, comarca de Aguilar de Campóo y valle del Pisuerga, junto al yugo palentino, que ellos llaman camellón o con orejas, y que se ha empleado para el carro, han preferido el de tipo burgalés para arar, si bien a veces también se han usado variantes del tipo suroccidental, tipo 4 , con corniles salientes delanteros que apoyan sobre los cuernos; pude estudiar ejemplares de estos tres tipos en San Pedro de Moarves. El carpintero jubilado de Nestar, al norte de Aguilar, me informó de que en los valles mineros, junto a estos tres tipos, se empleó también el yugo vizcaíno, que se importaba de Bilbao por el ferrocarril minero de La Robla.

\section{Tipo nororiental o burgalés}

Este tipo de yugo se ha empleado en amplios territorios burgaleses, comarcas de los Páramos de la Lora, Valles del Arlanzón y del Arlanza, Sierra de la Demanda, etc., así como en comarcas limítrofes de Cantabria, Palencia y La Rioja, que antaño formaron parte de la antigua diócesis burgalesa. 
Los principales rasgos que caracterizan al yugo de tipo burgalés son las camellas con una curvatura media, con solapa posterior rematada por arriba con un reborde prominente y perfil interior, ligeramente curvado hacia atrás. La contracamella también es curva, con pezones superiores a ambos lados. Los extremos del yugo forman una sola oreja, no dos como los del tipo anterior, el noroccidental, que se va adelgazando hacia arriba. El yugo carretero tiene la mesilla central redondeada en su parte superior, labrada en la misma pieza (figura 14). El subtipo de arar (figura 15) presenta la preceptiva hembrilla para atar la mediana, que traspasa toda la pieza hasta la cara posterior, excepto algún ejemplar como el de la figura 15.2, cuya hembrilla es un agujero vertical horadado en el ensanchamiento central posterior y reforzado con una chapa metálica; sobre la hembrilla, suelen tener forma acunada para llevar allí el arado. En las comarcas de la Lora y la Ojeda, grandes productoras de patatas, existe para excavarlas un yugo de gran longitud, alrededor de los dos metros, que, por lo demás, presenta todos los rasgos característicos.

\section{Tipo francés}

Dentro de la provincia burgalesa hay dos zonas con personalidad etnográfica parcialmente diferente, que presentan tipos de yugos distintos. Al sur está la Ribera del Duero, de la que más adelante trataré, y al norte, las Merindades y la Bureba, ambas en el valle del Ebro. En estas dos, como en otras de Cantabria, País Vasco y La Rioja, se han usado en el siglo $\mathrm{xx}$ yugos de tipo francés ${ }^{3}$, cuyo rasgo distintivo es la pareja de salientes delanteros, pomos los denomina Aranzadi (1931: 340-342), que hay a los lados de cada camella y que se apoyan sobre los cuernos del animal; las camellas son similares a las del anterior, de curvatura media y reborde superior (figura 16). El yugo de la figura 17 procede de Villarcayo y está pintado de blanco, rojo y azul en los extremos; tiene todos los elementos de los yugos transpirenaicos pero con uno típicamente castellano, que es la mesilla, ese grueso tarugo central que se ataba con el sobeo a la viga del carro.

Este tipo de yugo se ha empleado por todo el alto valle del Ebro; los de la figura 18, proceden de Cantabria y La Rioja; el primero es muy alto, con las camellas ojivales y muy fino; el otro, más tosco y en peor estado de conservación, es también alto y fino, por lo que se ha curvado en el centro. Este mismo tipo existió también en el País Vasco, donde evolu-

\footnotetext{
${ }^{3}$ Como es lógico en Francia hay más de un tipo de yugo (incluso los hay que no son cornales). Para ver las variantes francesas, consultar Brunhes-Delamarre (1969).
} 


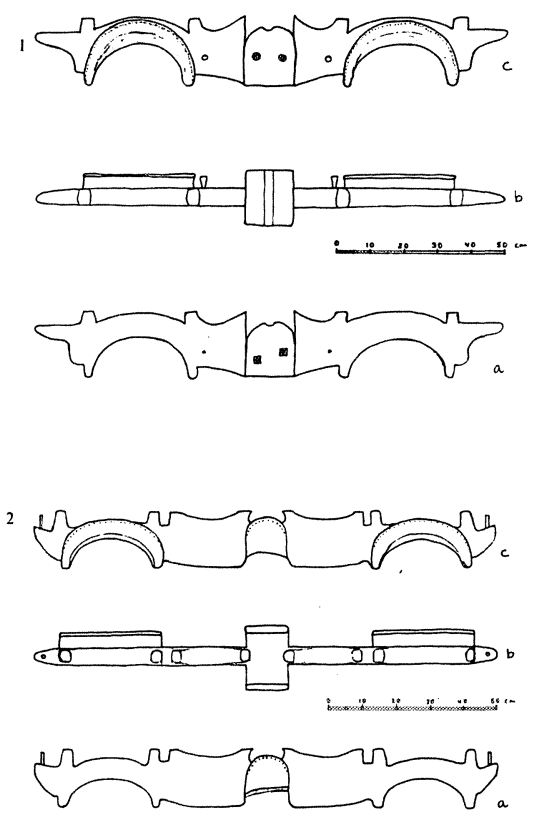

FiguRA 14.-Yugos carreteros de tipo nororiental o burgalés: 1. De Villadiego (Museo de Villadiego); 2. De Pinilla de los Moros (Colección Etnográfica de San Andrés de Cameros).
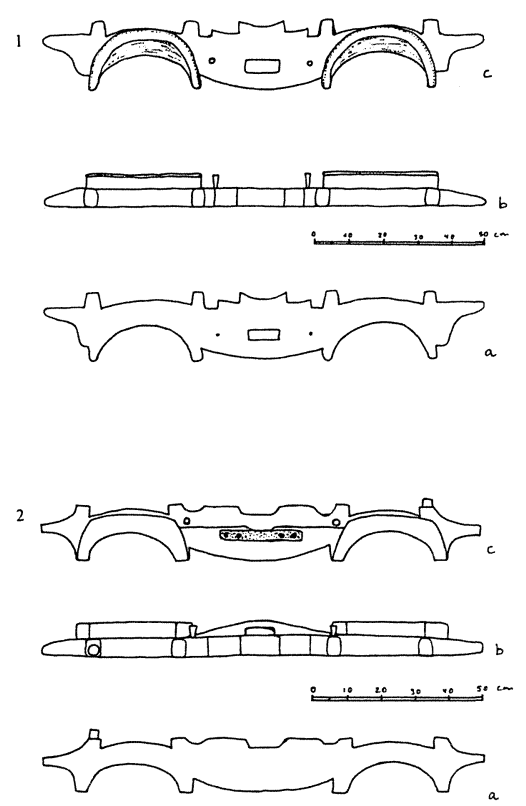

Figura 15.-Yugos de arar de tipo nororiental o burgalés: 1. De Villadiego (Museo de Villadiego); 2. De San pedro de Moarves, Palencia. 
cionó al vizcaíno actual, más alto, con su gran camella posterior ojival y la abundante decoración geométrica, que es moderna; desde el País vasco se exportaba a comarcas vecinas de La Rioja, Burgos y Cantabria. Tanto Aranzadi como Caro Baroja reconocen esta dependencia y el segundo, hablando de ciertos aspectos de la cultura pastoril, afirma que es muy posible que tengan más vieja raigam-
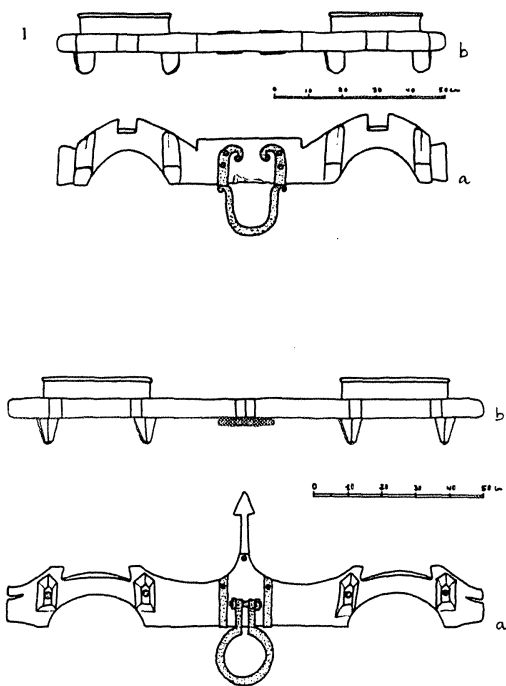

Figura 16.-Yugos franceses de Puy de Dôme, Auvernia (Museo Nacional de Artes y Tradiciones Populares, París). bre que carros, yugos y arados", que no parecen responder a una tradición demasiado antigua en el País Vasco (Caro Baroja 1981: 58).

\section{Tipo suroccidental}

Ocupa el área suroccidental de la Comunidad de Castilla y León, provincias de Salamanca, Ávila, parte oriental y meridional de Zamora y sur de Valladolid, si bien se ha extendido por el centro de la cuenca del Duero hasta llegar a Burgos y Palencia. Podría denominarse también yugo de corniles por los dos salientes delanteros que tiene cada camella y que apoyan sobre los cuernos, pero que tienen forma muy distinta de los salientes o pomos de los yugos de origen francés. Estos salientes, denominados fardas en Salamanca (García Martín 1983: 147), llevan una muesca curva que se proyecta hacia delante unos tres o cuatro centímetros hacia la mitad de la altura de las camellas, continuando por encima de éstas como una visera. La curvatura de la camella es similar a la del tipo bur-

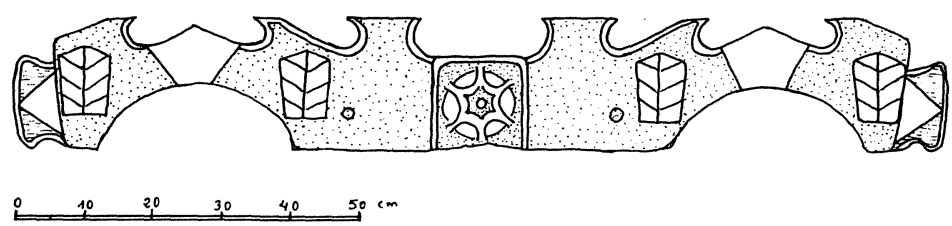

Figura 17.-Yugo de tipo francés de Villarcayo, Burgos. 

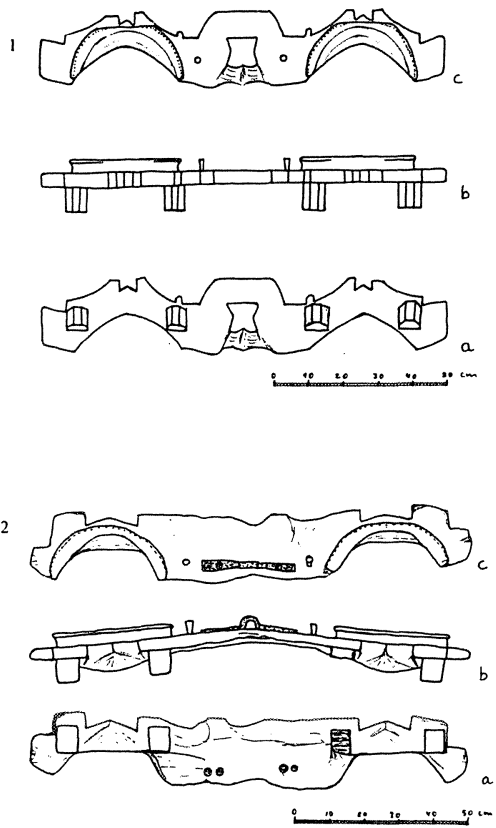

Figura 18.-Yugos de tipo francés: 1. De Cantabria; 2. De Soto de Cameros (Museo de la Rioja, Logroño).

galés y tiene una solapa posterior muy poco saliente, a veces no pasa de los dos centímetros. El corte central de la camella muestra un perfil curvado, de media luna o en forma de ese, mucho más elaborado y complejo que el resto de los yugos vistos (figura 19), que permite bastante giro sobre la testuz del buey según las características físicas de éste y el tipo de trabajo. Las orejas de ambos extremos son, al contrario que en el burgalés, bajas y redondeadas

En algunos lugares de esta región aparecen yugos que responden en general a este tipo, pero no presentan los corniles o fardas tan característicos, hasta el punto de que quizá se trate de un tipo anterior, antecedente del que nos ocupa. De Lumbrales, en el oeste de la provincia salmantina, son los yugos de bueyes de la figura 20 , uno de carro y otro de arar; como se ve en la vista superior (b) de la figura, la cara delantera de ambos yugos es totalmente plana. He visto alguno similar para arar las viñas en el sur de la provincia de Zamora.

Si comparamos los yugos de la figura anterior con los de las siguientes, vistos de frente (a), es inconfundible la ceja o visera curvada que recorre toda la camella por arriba, baja hacia los lados acabando en los 

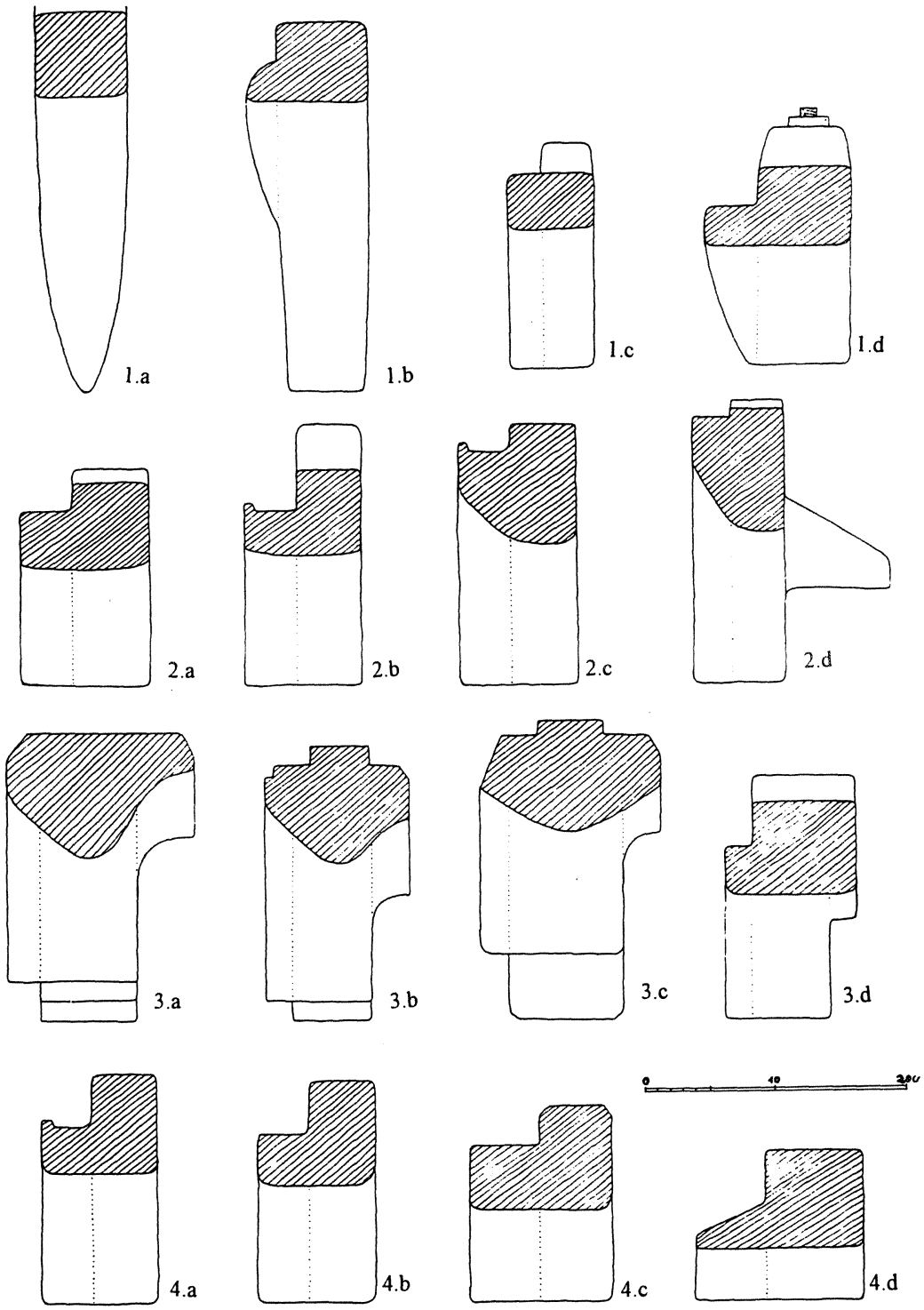

Figura 19.-Corte por el centro de la camella de diferentes tipos de yugos. 1. De tipo noroccidental: 1.a. Benavente; 1.b. Tierra de Campos, Valladolid, de subtipo leonés; 1.c. Cervera de Pisuerga ; 1.d. S. Pedro de Moarves de subtipo palentino. 2. De tipo nororiental: 2.a. S. Pedro de Moarves; 2.b. Tubilla del Lago; 2.c. Villadiego ;2.d. De tipo francés: Cantabria. 3. De tipo suroccidental, que son los de sección más compleja: 3.a y 3.b Salamanca; 3.c. Hontoria de Valdearados; 3.d. San Pedro de Moarves. 4. De tipo suroriental: 4.a. Valderrueda; 4.b. Sangarcía; 4.c. Ribera burgalesa; 4.d. Brazacorta. 

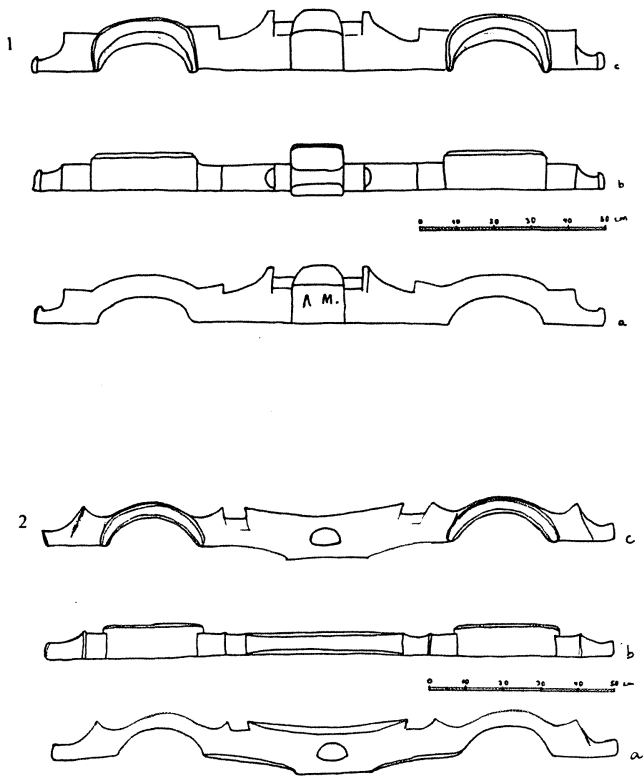

Figura 20.-Yugos de Lumbrales, Salamanca, de tipo suroccidental pero sin corniles.
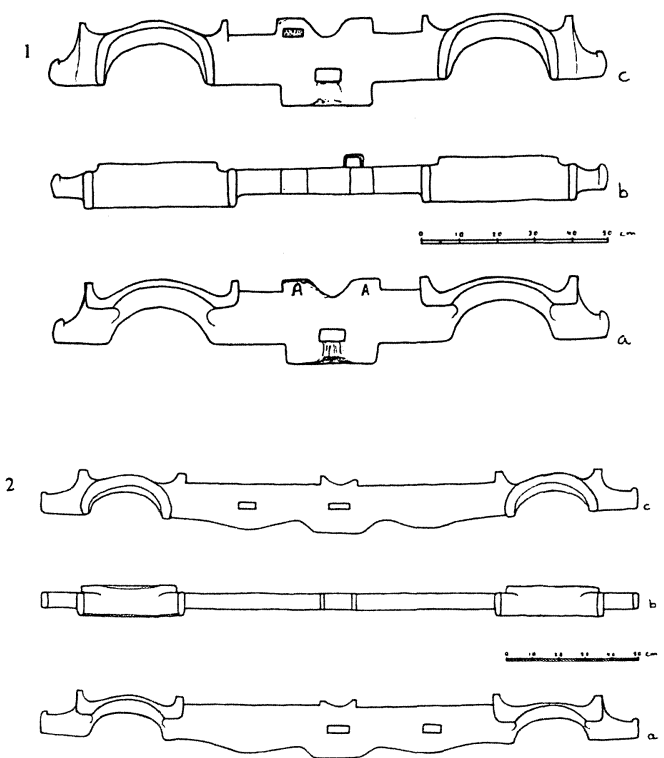

Figura 21.-Yugos de tipo suroccidental: 1. De arar, procedente de Salamanca; 2. De arar las viñas, de la Tierra del Vino zamorana (Colección Etnográfica de Caja España, Zamora). 

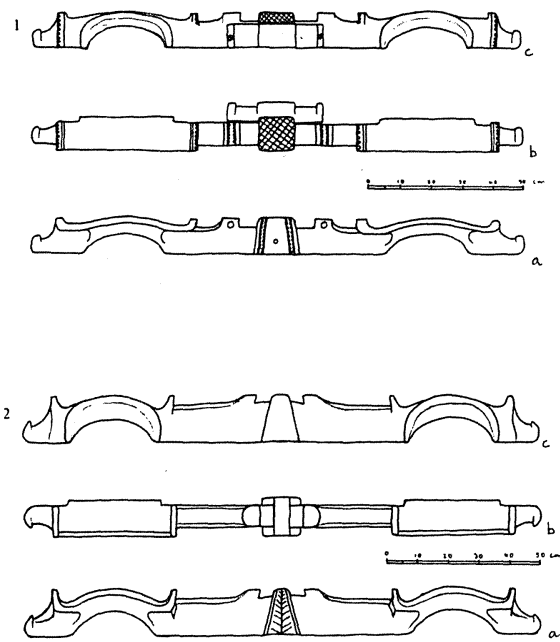

Figura 22.-Yugos carreteros de tipo suroccidental: 1. De Salamanca; 2. De Hoyos del Espino, Ávila. corniles, curvos y salientes, cuya función ya hemos comentado; la vista superior (b) nos muestra que la parte delantera del yugo no es recta, sino que esa visera con los corniles se proyecta hacia delante tres o cuatro centímetros, mientras que la solapa trasera siempre es muy pequeña, de dos o tres centímetros.

Los yugos de arar, con sus variantes funcionales de aricar, de hasta 175 centímetros, suelen ser fuertes, pero no tanto como los de carro, y bastante toscos (figura 21). En la zamorana Tierra del Vino, se empleaban para arar las viñas unos yugos muy largos, de más de dos metros (figura 21.2),

para arrayar o coger calles, es decir, arar en primavera cerca de las cepas (Álvarez Tejedor 1989: 169). Los yugos de carro son más pesados, fuertes y casi siempre, sobre todo en la zona salmantina, presentan abundante ornamentación pintada o esculpida. La longitud oscila entre los 150 y los $160 \mathrm{cms}$. y se caracterizan por la voluminosa mesilla central, que, si en los yugos palentinos tenía un contorno cuadrangular y en los burgaleses era redondeada por arriba, en éstos adquiere formas triangulares o rectangulares con caprichosos remates superiores. Un subtipo más antiguo es el representado por los yugos de la figura 22, bajos y con decoración geométrica muy simple; éstos contrastan con los más modernos, altos, barrocos, muy decorados (figura 23) que se empleaban en carros pintados,

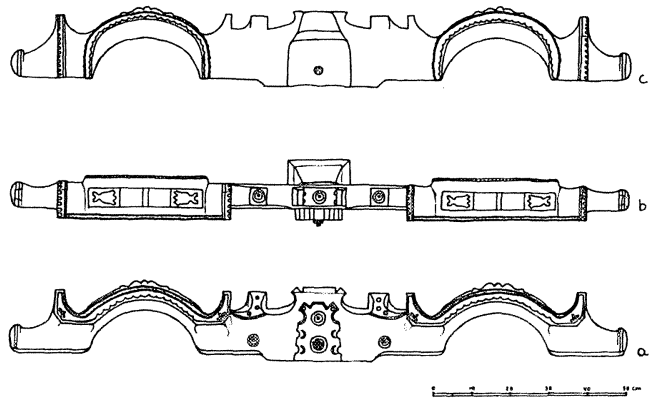

FIGURA 23.-Yugo carretero de tipo suroccidental, procedente de la provincia de Salamanca, que presenta abundante decoración tallada. 
orgullo del labrador, con los que acudía a mercados, fiestas y, a veces, también a concursos. Este tipo de yugo, que parece originario de Salamanca, se ha extendido por las provincias de Valladolid, comarcas al sur del Duero y el valle del Pisuerga, hasta Burgos y Palencia. De Hontoria de Valdearados (Burgos) procede uno, similar a los salmantinos por su abundante decoración tallada (Martín Criado 1997: 128). Una curiosa versión local para arar con vacas es el que pude estudiar en San Pedro de Moarves, al norte de Palencia, obra del carpintero del vecino pueblo de Olmos de Ojeda (figura 24.1). Aparte de éstos, hay otros subtipos, como el yugo para un solo animal (figura 24.2), el yugo mixto para vaca y burro, que se consideraba como "síntoma de una pobreza extrema" (Gómez Hernández, Gómez Gutiérrez y López Gavilán 1991: 201), y el yugo de tres camellas para doma, al que alude de forma lacónica algún autor salmantino ${ }^{4}$, si bien otros no lo citan.
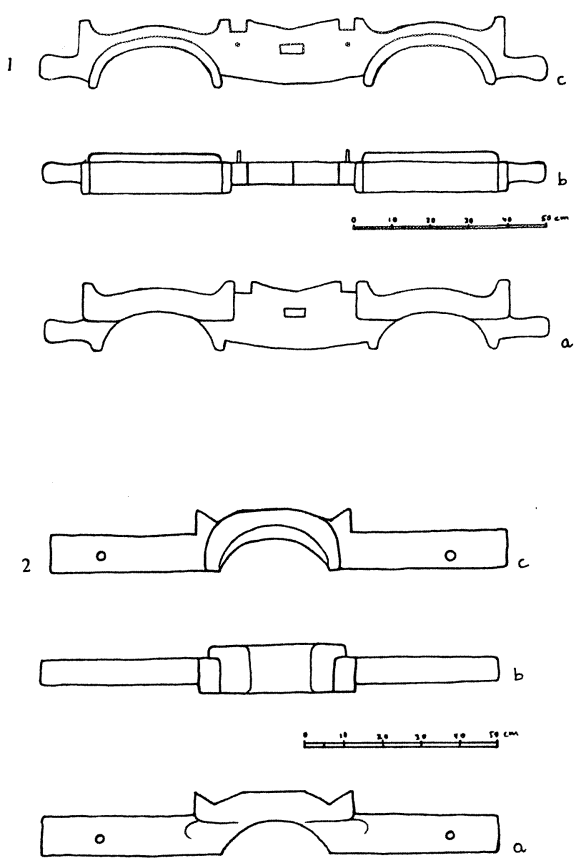

Figura 24.-Yugos de tipo suroccidental: 1. Para arar; versión local, ligera y simplificada de San Pedro de Moarves, Palencia; 2. Para un animal (Colección Etnográfica de Caja España, Zamora).

${ }^{4}$ J. C. Martín Aparicio dice literalmente: "La faena consistirá en uncir, en un yugo especial de tres huecos, al novillote entre los bueyes viejos y enseñados" (1987: 17). 


\section{Tipo suroriental}

Este tipo de yugo se encuentra en toda la provincia de Soria, en la Ribera burgalesa, en la provincia de Segovia y llega hasta la de Ávila, donde convive con el tipo anterior. Es el más arcaico de todos los existentes en Castilla y León y, también, en España en general, donde aparece en varias regiones, como luego veremos. Esa sensación de arcaísmo viene dada en parte por su tosquedad, sus formas rectilíneas y su labra simple. A veces tiene el aspecto de un madero apenas desbastado con la azuela, sobre todo en algunos ejemplares de la Ribera soriana y burgalesa que tienen unas camellas muy poco curvadas, en lo que coinciden con los aragoneses. Sin embargo, en otras zonas, en el centro de Soria o en Segovia, la curvatura de las camellas es de tipo medio. Siempre tienen solapa trasera, de unos tres o cuatro centímetros, raras veces de más, que puede tener resalte superior en algunas comarcas.

En las comarcas orientales y centrales de Soria, los yugos carreteros son muy aparatosos, de 160 centímetros de longitud o más, pensados para grandes bueyes, con camellas bastante curvadas y una muesca que cruza la contracamella por la que pasaba la coyunda. La mesilla para atarlo a la lanza del carro suele ser cuadrangular, como un dado; cuando el yugo ha tenido mucho uso, presenta un acusado desgaste por el roce con la lanza (figura 25). Los yugos de arar son más ligeros; la forma de las camellas y contracamellas es similar y la hembrilla, como es frecuente en este tipo, no atraviesa el centro del yugo hasta la cara posterior, sino que tiene forma de ángulo recto y sale por la cara inferior (figura 26).

En la Ribera soriana y burgalesa (Martín Criado 1997: 127-132), los yugos suelen ser más ligeros, porque se usaron más las vacas en la labranza; además, presentan algunos rasgos peculiares. El más perceptible es la poca curvatura de las camellas, cuya solapa posterior, en bastantes ejemplares, va disminuyendo en grosor hacia afuera. La contracamella puede ser curva, si bien en muchos casos está formada por dos o tres tramos rectos. Los de carro suelen tener una longitud entre 135 y 150 centímetros y, por lo demás, son parecidos a los anteriores (figura 27), si bien hay algunos que presentan camellas con mayor curvatura y la mesilla tiene un remate superior en doble semicírculo (ibid.). Los yugos de arar y de aricar tienen también camellas muy poco marcadas, con solapas muy finas, algunas en disminución, y hembrilla en ángulo, como es habitual en todo el tipo. Los de arar son cortos, alrededor de $120 \mathrm{cms}$. (figura 27.2) y los de aricar rondan los 140; algunos de estos últimos tienen 

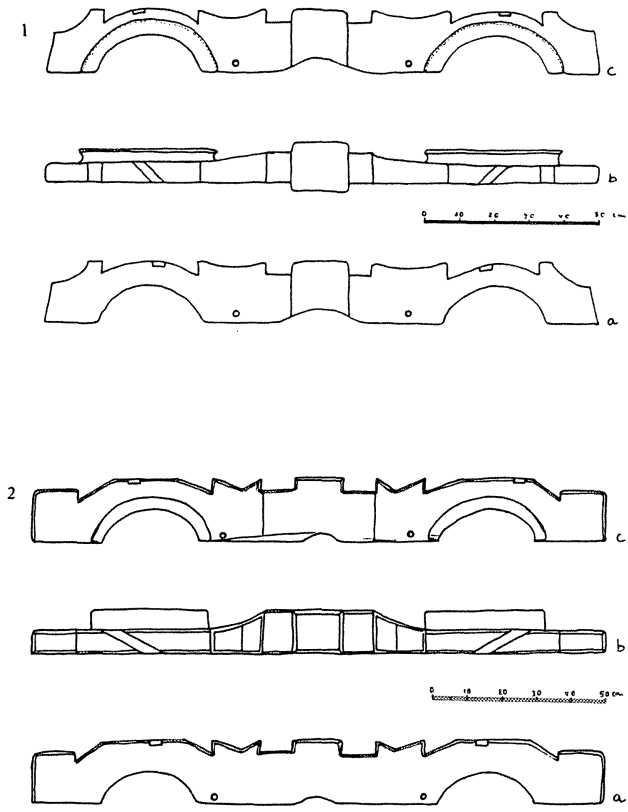

FIgURA 25.-Yugos carreteros de tipo suroriental de la provincia de Soria: 1. De Valderrueda; 2. De Santa María de Huerta.
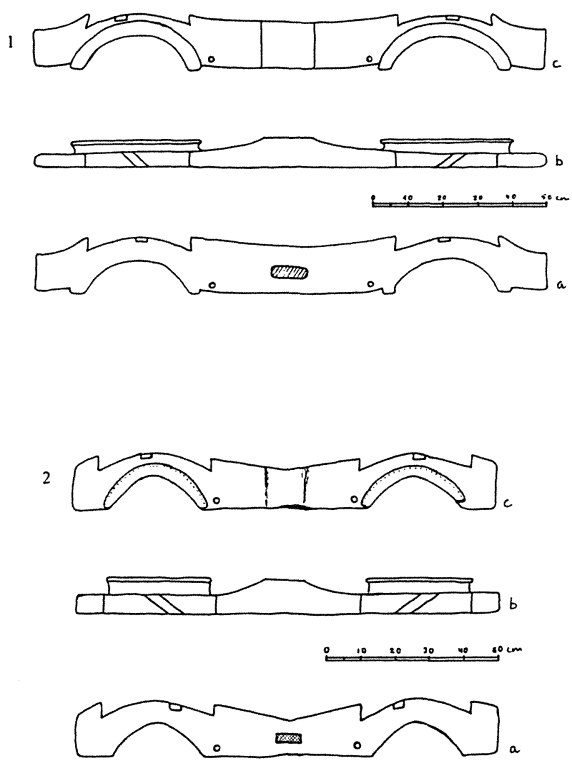

Figura 26.-Yugos de tipo suroriental de Soria: 1. De Valderrueda, para aricar; 2. De Santa María de Huerta, para arar. 
1
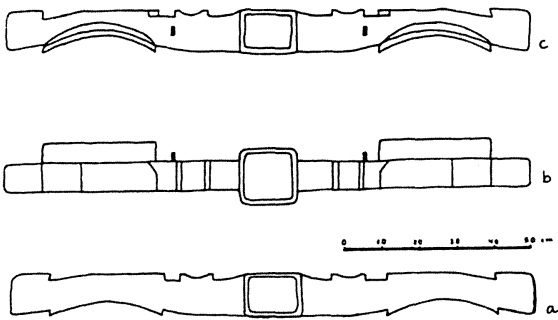

2
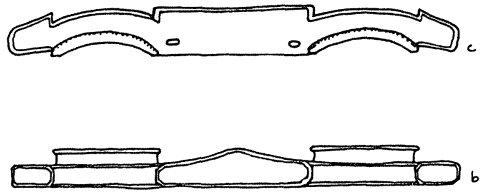

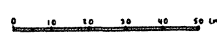

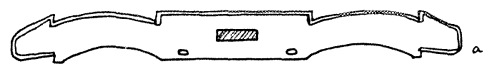

FIGURA 27.-Yugos de tipo suroriental de la Ribera del Duero: 1. De Brazacorta, Burgos; 2. De Atauta, Soria.

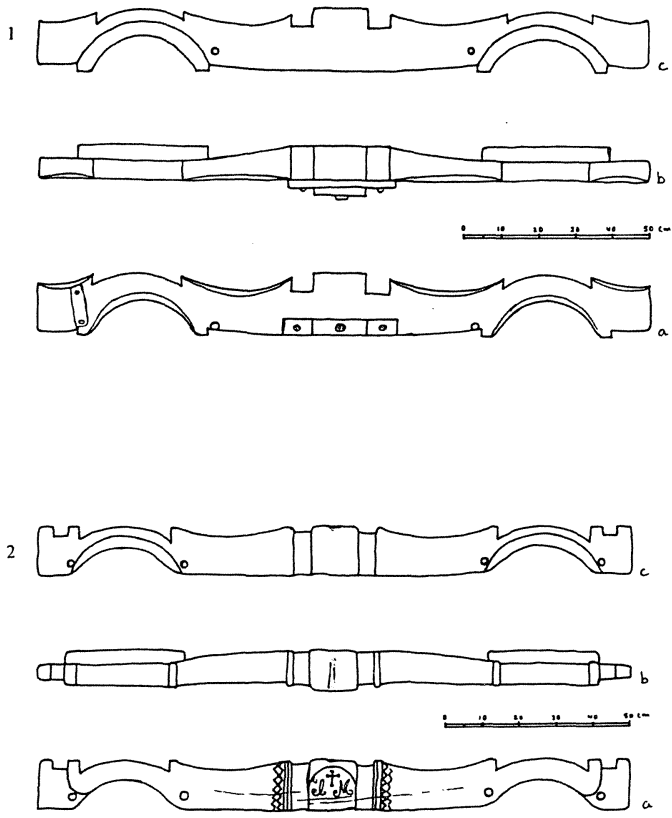

Figura 28.-Yugos de tipo suroriental para carro: 1. De Sangarcía, Segovia (Colección Muñoz Gordo); 2. De Diego Álvaro (Museo de Ávila). 
una segunda hembrilla descentrada por si fuera necesario desplazar el arado para que coincidiera con los surcos.

En Segovia y Ávila, la camella es más curvada, como en los de Soria; los yugos carreteros miden entre 160 y $165 \mathrm{cms}$. y su mesilla es también cuadrangular (figura 28). El del Museo de Ávila presenta como particularidad, aparte de la decoración, un rebaje a ambos lados exteriores de las camellas, con lo que su forma tiene cierta semejanza con los del tipo suroccidental, que como ya he dicho, se extienden también por esta provincia. En la colección de Alberto Munoz, de Sangarcía, se halla una muestra muy representativa de yugos de arar (figura 29); el menor y más ligero era para abrir el surco y tapar la simiente de cereal sembrada a voleo; el siguiente es un yugo de arar de $125 \mathrm{cms}$. con la hembrilla en escuadra; el tercero, de 165 centímetros de longitud, es de aricar con un solo arado, y el cuarto, de $211 \mathrm{cms}$., es también de aricar pero con dos arados, para lo cual lleva dos hembrillas equidistantes de las camellas ${ }^{5}$. Esta última clase de yugo se empleaba para aricar las tierras de cereal llanas y ligeras, de manera que el labrador guiaba un arado con cada mano y los bueyes podían muy bien arrastrarlos, porque el arique era una labor superficial para arrancar las malas hierbas.

Una variante bastante frecuente es la de los yugos mixtos, por lo general para una vaca y un borrico, para arar y aricar (figura 30.1). Son característicos de economías débiles o de comarcas donde abundaba el viñedo, cuyas labores se hicieron a brazo hasta el siglo $\mathrm{xx}$, por lo que la fuerza animal que estos labradores necesitaban era pequeña. Así lo explica una persona que fue labrador:

Los que tenían unas tierrecillas pequeñas y una economía débil recurrían a este sistema. Tenían la vaca para que les diera un ternero $y$, a la vez, sacar un poco de leche para la alimentación, y el burro para transportar algo de leña y trasladar al dueño a algún lugar (Muñoz Gordo 1994: 25).

Al ser dos animales de fuerza semejante, parece que el resultado no era malo, teniendo en cuenta que se trataba siempre de pequeñas explotaciones. Explicaciones semejantes han dado otros autores (Castellote Herrero 1985: 96).

Otra variante, que ya hemos visto en algunos de los tipos anteriores, es la del yugo para un solo animal, que se empleaba en trabajos pequeños de arada de huertas o viñas. Para trabajar viñas con un arado de varas de tipo horcate, seguramente se utilizó el yugo de la figura 30.2, que

5 (Muñoz Gordo 1994: 22-26). Cuando visité la colección etnográfica que guardaba en su casa, el autor ya había fallecido y fue su viuda, Sabina Pérez, quien me la mostró amablemente. 

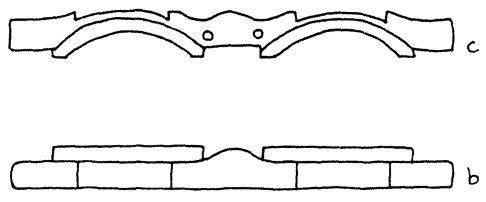

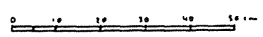

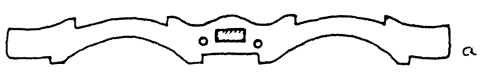

2
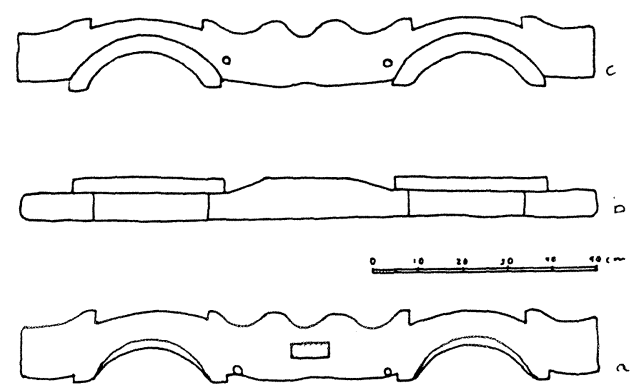

3
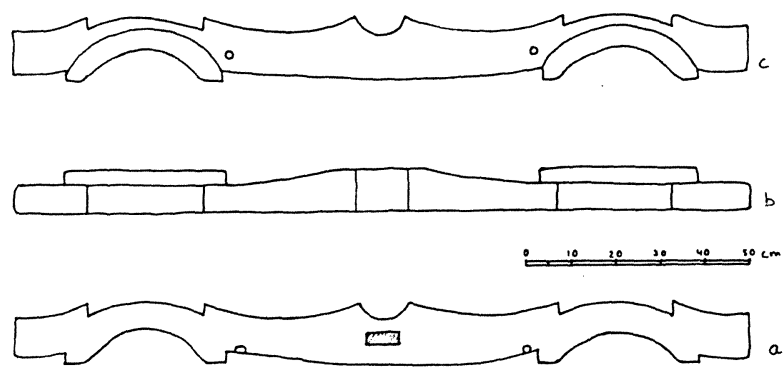

$+$
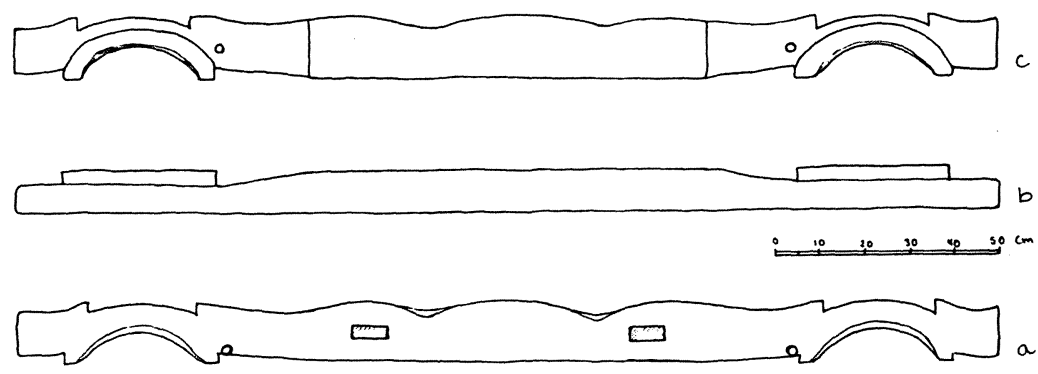

Figura 29.-Conjunto de yugos de tipo suroriental de Sangarcía: 1. De abrir el surco al sembrar; 2. De arar y trillar; 3. De aricar con un arado; 4. De aricar con dos arados (Colección Muñoz Gordo). 

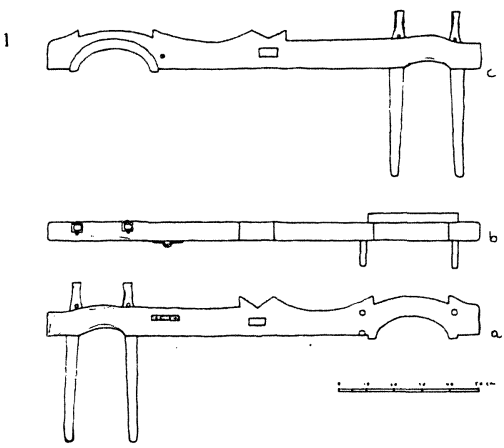

2
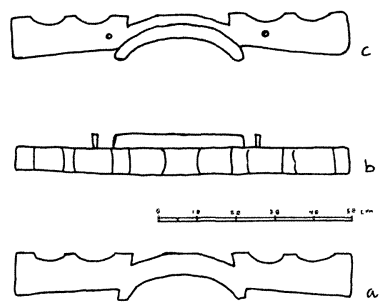

FIGURA 30.-Yugos de tipo suroriental: 1. Yugo mixto para aricar, de Sangarcía, Segovia; 2. De un animal, de la Ribera burgalesa.

procede de la Ribera del Duero burgalesa. Presenta la característica camella poco curvada, la contracamella formada por tres segmentos rectilíneos y una labra a azuela muy basta; es probable que fuera hecho por el propio labrador, como sucedía a menudo, dada su tosquedad.

Es muy posible que, en algunos lugares de Castilla y León donde se ha utilizado este tipo de yugo, haya existido uno de doma de tres camellas, pues pertenecen a este mismo tipo los estudiados por J. L. Mingote Calderón en la Sierra Norte de Madrid (1992: 14-16), así como el del Museo de Teruel. Sin embargo, en el sur de La Rioja, en los pueblos del puerto de Piqueras, en el límite con la provinncia de Soria, no era igual. En San Andrés de Cameros, y en otros pueblos de la zona, había un yugo comunal de doma que usaba el vecino que lo necesitara. La particularidad de este yugo es que tenía una camella a un lado y otras dos al contrario, con hembrilla en el centro (figura 31). Desgraciadamente este yugo ha

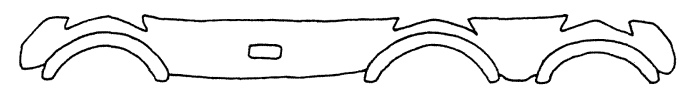

Figura 31.-Yugo de doma de tres camellas descentradas que se empleaba en San Andrés de Cameros, La Rioja, según Tejado Ceña. 
desaparecido y el dibujo lo he tomado de un autor local (Tejado Ceña 1993: 13-15), con quien pude hablar en el verano del año 2000 en dicho pueblo; él me confirmó todos los detalles, lo mismo que otras personas ancianas que alli estaban. En el Museo de Teruel hay un punzón ibérico (Atrián Jordán y Untermann 1982: 55-59), procedente del Alto Chacón, con una inscripción en lengua ibérica en cada cara, que es totalmente plana, y que se asemeja sorprendentemente a un yugo con dos camellas juntas a un lado; el contrario está roto (figura 32). También en Guadalajara se emplearon yugos de doma de tres camellas, según E. Castellote Herrero (1985: 95); sin embargo, en la sierra segoviana no parece que se utilizaran, de acuerdo con el testimonio de P. Andrés Cobos (1967).

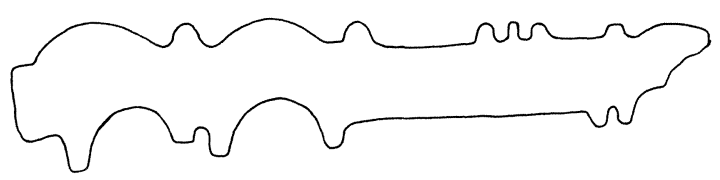

Figura 32.-Punzón de hueso ibérico de Teruel que muestra semejanza con el yugo de la figura anterior (Museo de Teruel).

Yugos similares a los del tipo suroriental los encontramos en muchas regiones de España, desde Aragón a Canarias; en algunas se advierten ciertas particularidades, sin que por eso desmienta su naturaleza común. En Aragón, los yugos son rectilíneos, poco trabajados y de factura tosca; en ciertas zonas con las camellas muy poco curvadas (figura 33), como las que hemos visto en la Ribera del Duero. Relacionados con los aragoneses parecen los yugos valencianos con que se uncían los bueyes que sacaban las barcas de pesca, como muestran los cuadros de Sorolla y algunas fotografías ${ }^{6}$ de la segunda mitad del siglo XIX o principios del XX.

El mismo tipo de yugo está extendido por las comunidades de Madrid y de Castilla-La Mancha; en la sierra madrileña han sido documentados por J. L. Mingote Calderón (1995: 115, 118). En la figura 34 presento un yugo de arar de Guadalajara, dibujado según varias fotografías de E. Castellote Herrero (ibid.: 125), que tiene rasgos semejantes a los de los yugos sorianos. En el Museo Etnográfico de los Montes de Toledo, de

${ }^{6}$ Dos versiones de La vuelta de la pesca se reproducen en el catálogo de una de las últimas exposiciones del pintor valenciano: Joaquin Sorolla (1863-1923). Madrid, Fundación Cultural Mapfre Vida, 1995: 71 y 79. En cuanto a la fotografía, puede verse Huella del tiempo. Aspectos etnográficos de la colección Díaz-Prósper. Valencia, Diputación Provincial, 1997: 47, 70 y 101. 
Guadamur, pude ver y dibujar los dos ejemplares de la figura 35; semejantes son varios ejemplares exhibidos en el Centro de Interpretación del Parque Nacional de Cabañeros, en Ciudad Real. Creo que también se deben incluir aquí los yugos andaluces
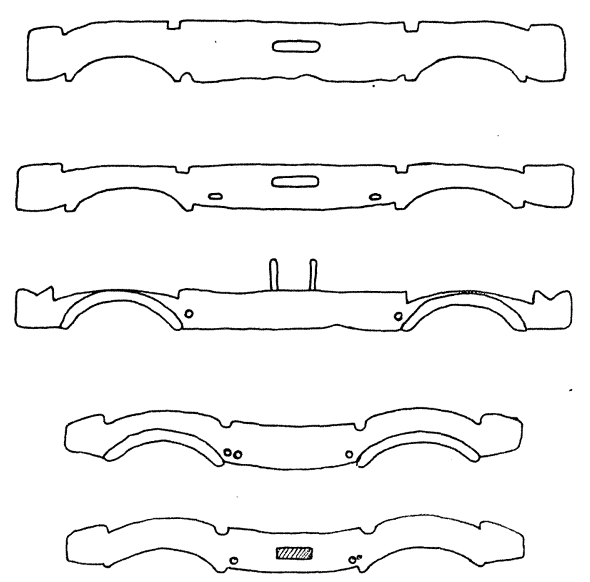

Figura 33.-Yugos cornales aragoneses, según M. Alvar et al. (1979). que he visto en las carretas tiradas por bueyes que peregrinan al Rocío; en el Atlas Lingüístico $y$ Etnográfico de Andalucía, no aparecen muchas imágenes de yugos cornales, pero las que hay (figura 36) reproducen yugos del mismo tipo.

En las Islas Canarias, donde estuvo muy extendida la labranza con bueyes y el arrastre con parejas de vacas y de bueyes se ha conservado como deporte rural, se halla el mismo tipo de yugo. He podido estudiar en directo algunos ejemplares de las medianías de Gran Canaria, en concreto, en Teror y en Ingenio. Los yugos carreteros (figura 37.1) son largos, $160 \mathrm{cms}$., y pesados, parecidos a los de Soria y Segovia. Los de arar, cuya longitud ronda los 120 centímetros, tienen las camellas con bastante curvatura y la contracamella recortada artísticamente (figura 37.2); a veces, la decoración, de tipo geométrico, se extiende también a la cara posterior, que es la que el labrador ve cuando va arando.
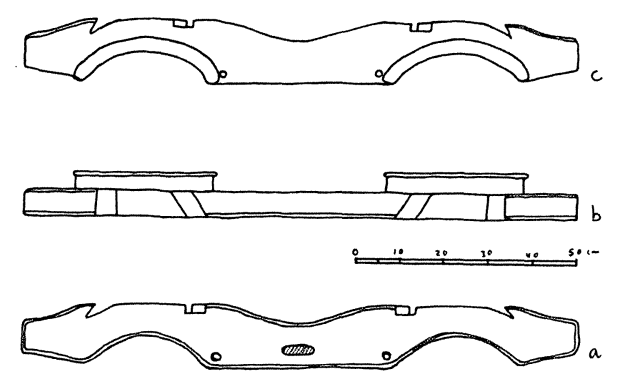

Figura 34.-Yugo de arar de Guadalajara; dibujo del autor según fotografías de $\mathrm{E}$. Castellote Herrero.

Resumiendo lo hasta aquí expuesto, resulta que en Castilla y León hay cuatro grandes tipos de yugos cornales que han tenido uso en amplias áreas de su territorio (figura 38). El tipo noroccidental se extiende por las provincias de León, Zamora, Valladolid y Palencia, y, fuera de la comunidad, por Asturias y Cantabria, por lo que la denominación de astur- 
1
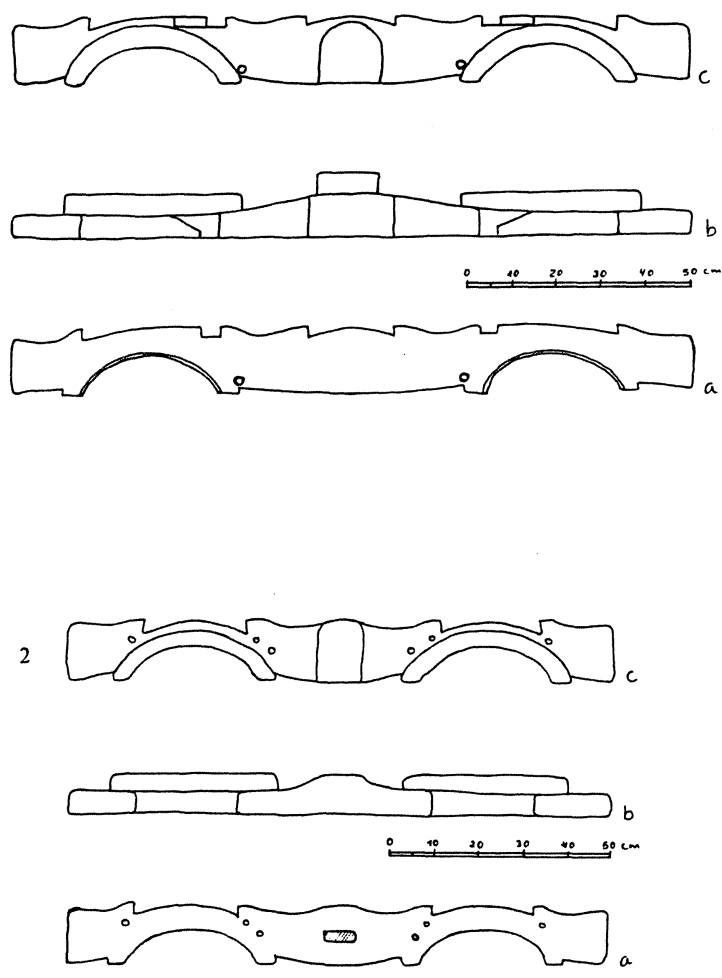

Figura 35.-Yugos de carro y de arar, del Museo de los Montes de Toledo, Guadamur.

1

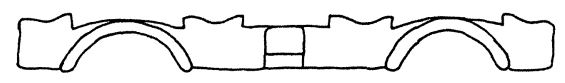

2
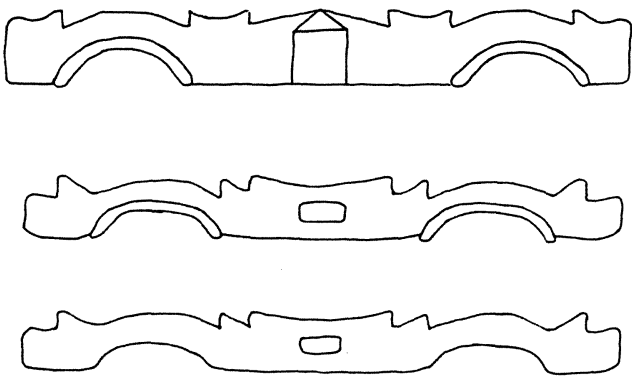

FiguRA 36.-Yugos cornales andaluces, según M. Alvar, A. Llorente y G. Salvador. 

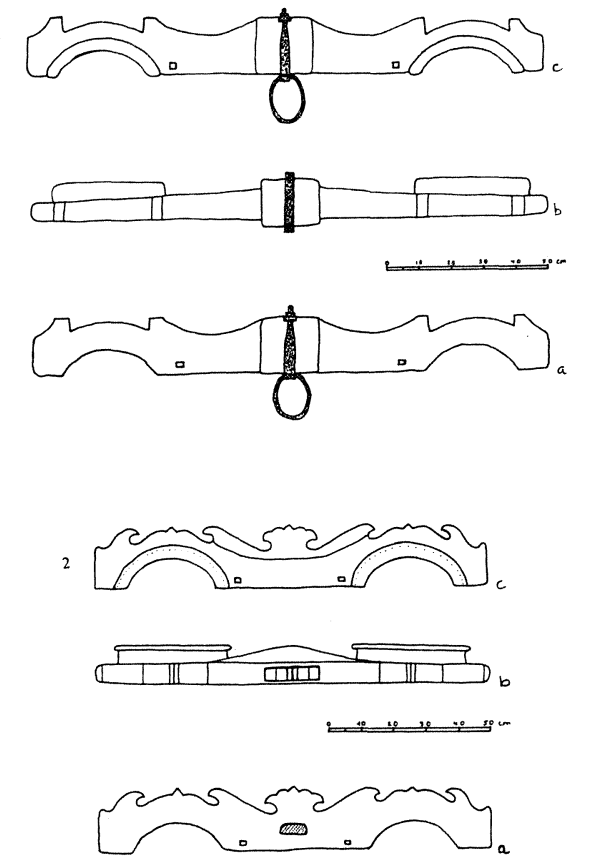

Figura 37.-Yugos de Gran Canaria (Casa Museo de los Patronos de la Virgen del Pino de Teror): 1. Carretero; 2. De arar. caíno.

El yugo cornal es un apero antiguo y, seguramente, dada su relativa simplicidad, de los que menos han evolucionado, si bien, lo que acabamos de ver nos habla de una mayor variedad formal de lo que muchos creen. Quizá podría relacionarse la tipología de los yugos con rasgos culturales e históricos de otra índole, pero no hay que olvidar que una cultura es un todo complejo y continuo, una red de interdependencias, y no se la puede caracterizar por un tipo de apero, de vasija o de arma; ni siquiera sólo por una lengua. El estudio tipológico de un solo apero es probable que no nos diga gran cosa; ahora bien, si tuviéramos estudios de la mayoría, y dentro de investigaciones más amplias y ambiciosas, su información creo que sería relevante y provechosa. 


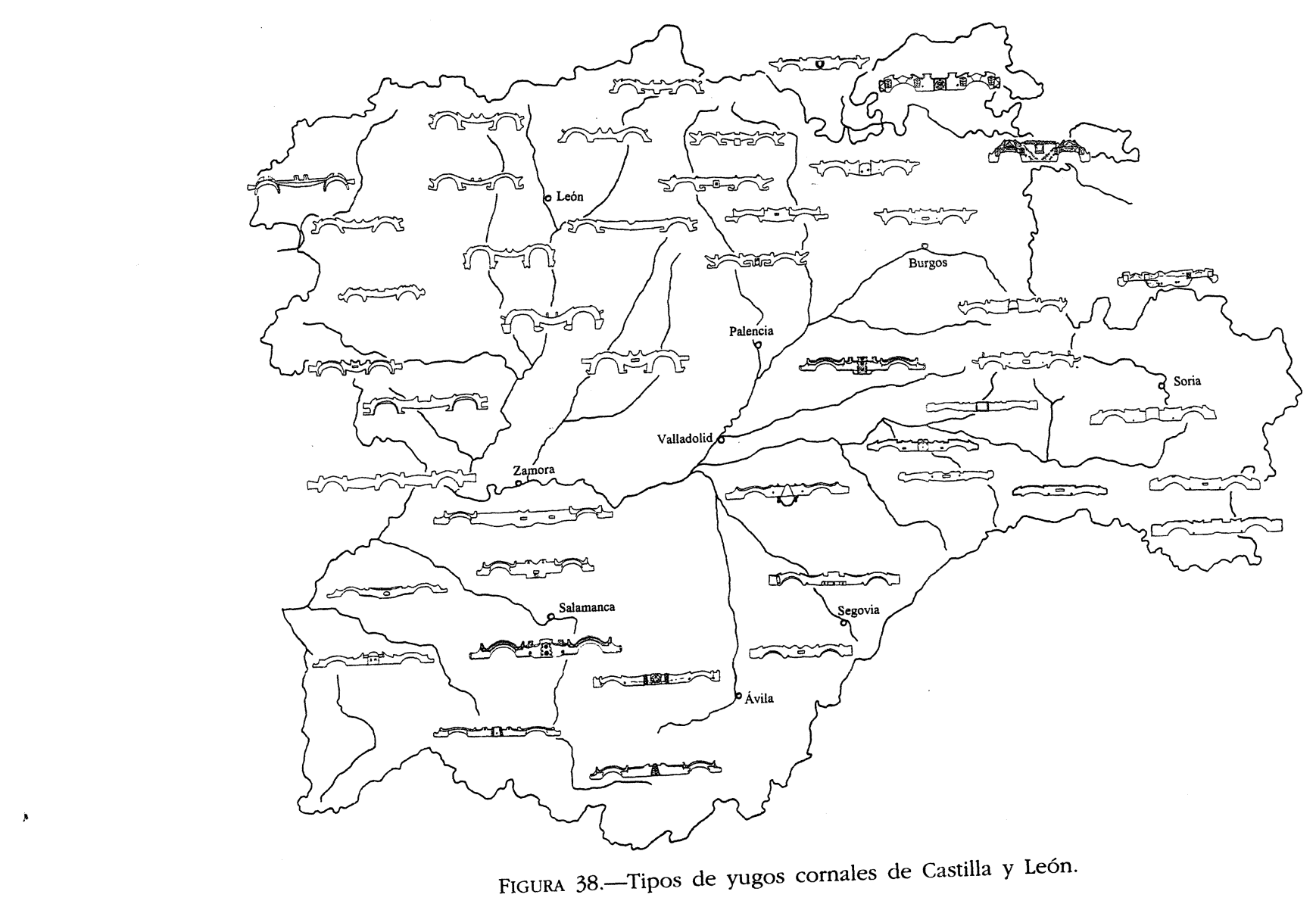


ARTURO MARTÍN CRIADO

\section{BIBLIOGRAFÍA CITADA}

Alvar, M.; A. Llorente y G. Salvador. 1961. Atlas lingüistico y etnográfico de Andalucia, I. Madrid: CSIC.

Alvar, M. et al. 1979. Atlas lingüistico y etnográfico de Aragón, Navarra y Rioja, I. Madrid: CSIC.

Álvarez, G. 1949. El habla de Babia y Laciana, León: Ediciones Leonesas. 1985.

Álvarez Cabeza, A. y F. J. García Martínez. 1994. Vocabulario de la Cepeda (provincia de León) Asturias.

ÁlVAREZ FERnÁNDEZ-CaÑEDO, J. 1963. El habla y la cultura popular de Cabrales. Madrid: CSIC

ÁlvAREZ TEjEDOR, A. 1989. Estudio lingüístico del léxico rural de la zona este de la provincia de Zamora. Salamanca: Universidad de Salamanca.

ANDRÉs CoBos, P. 1967. "Vocabulario segoviano". Estudios Segovianos 19: 279-302.

ARANZADI, T. de 1931. "Aperos de labranza y sus aledaños textiles y pastoriles", en A. Carreras Candi (dir.), Folklore y costumbres de España, I. Madrid: Merino. Edición facsímil de 1988.

ARIZA Viguera, M. 1988. Fonología bistórica del español. Madrid: Síntesis.

ATRIÁN JORDÁN, P. y J. UnTERMANN. 1982. "Un punzón de hueso con inscripción ibérica procedente del Alto Chacón (Teruel)». Teruel 67: 55-59.

BRUNHES-DelamarRe, M. J. 1969. Geographie et ethnographie de l'attelage au joug en France du XVIr siècle à nos jours. Praga.

Caro Baroja, J. 1981. Los pueblos de España. Madrid: Istmo, 3. a edición.

- 1983. Tecnología popular española. Madrid: Editora Nacional.

Casado lobato, M. C. 1948. El habla de la Cabrera Alta. Contribución al estudio del dialecto leonés. Madrid: CSIC.

CASTELlOTE HERRERO, E. 1985. "Carpintería rural de Guadalajara". Etnografía Española 5: $75-133$.

Columela, L. J. M. 1988. De los trabajos del campo. Edición de A. Holgado Redondo. Madrid: Ministerio de Agricultura y Ed. Siglo XXI.

Corominas, J. y J. A. PASCUAL. 1991. Diccionario crítico etimológico castellano e bispánico, VI. Madrid: Gredos.

FERNÁNDEZ GONZÁlez, A. R. 1959. El babla y la cultura popular de Oseja de Sajambre. Oviedo: IDEA.

FERNÁNDEZ GONZÁleZ, J. R. 1978. Etnografía de los Ancares. Santiago de Compostela: Universidad de Santiago, anejo de Verba, 10.

FERNÁNDEZ MONTES, M. 1992. “Pervivencia de los motivos ibéricos en la tradición popular", en La sociedad ibérica a través de la imagen. Madrid: Ministerio de Cultura.

García-Bellido, M. P. 1992. "La moneda, libro en imágenes de la ciudad", en La sociedad ibérica a través de la imagen. Madrid: Ministerio de Cultura.

GarCía MARTín, J. 1983. «El arado y el yugo en Navaombela. Denominación de sus partes y piezas". Salamanca. Revista Provincial de Estudios 9-10: 141-148.

GarCía ReY, V. 1934. Vocabulario del Bierzo. León: Lancia (1986, edición facsímil).

GARRIDO GARRIDO, J. M. 1983. Documentación de la catedral de Burgos (804-1183). Burgos: J. M. Garrido.

Gómez Hernández, A.; J. M. GÓMEZ GutiérReZ y E. LÓPEZ GaVILÁN. 1991. “Apuntes para una antropología cultural, en J. M. Gómez Gutiérrez (coord.), El libro de las dehesas salmantinas: 165-246. Salamanca: Junta de Castilla y León. 
GonZÁlez EChEgaray, J. 1971. "Yugos y arados en la provincia de Santander". Publicaciones del Instituto de Etnografía y Folklore Hoyos Sáinz 3: 123-168.

GONZÁlez PÉrEZ, C. 1997. "Los medios de transporte tradicionales", en F. Rodríguez Iglesias (dir.), Galicia. XXIV. Antropología. Tecnología Agraria. Oficios: 74-77. La Coruña.

Graña García, A. y J. Naveiras Escanlar. 1984. Museo Etnográfico de Grandas de Salime. Guía del visitante. Oviedo.

Herrera, G. A. 1513. Obra de agricultura. Edición y estudio de J. U. Martínez Carreras. Madrid: Atlas. 1970. BAE CCXXXV.

KLEMM, A. 1962. "Cultura popular de Ávila". Anales del Instituto de Lingüistica VIII: 1304.

KRÜGER, F. 1947. El léxico rural del noroeste ibérico. Madrid: CSIC.

LISTE FERNÁNDEZ, A. 1997. "Instrumental agrario”, en F. Rodríguez Iglesias (dir.), Galicia. XXIV. Antropología. Tecnología Agraria. Oficios: 168-171. La Coruña: 168-171.

LIZOAIN GARRIDO, J. L. 1985. Documentación del monasterio de Las Huelgas de Burgos (1231-1262). Burgos: J. M. Garrido.

MARTÍn APARICIO, J. C. 1987. Gentes y costumbres. Salamanca: Diputación Provincial.

MARTÍN CRIADO, A. 1995. "Aperos tradicionales de Villamorco (Palencia)". Revista de Folklore 15 (1): 183-200.

- 1997. "Ubios cornales de la Ribera del Duero (Burgos)». Revista de Folklore 17 (1): 127-132.

- 1999. "Vocabulario de la Ribera del Duero". Biblioteca. Estudio e Investigación 14. (Monográfico).

Mingote Calderón, J. L. 1988. "Aperos y faenas agrícolas en los fueros de la provincia de León". RDTP XLIII: 411-428

- 1992. "Yokes for Three Cows. A Disappeared Technique for Breaking in Cattle in La Sierra Norte of Madrid (Spain)n. Tools-Tillage VII (1): 3-28.

- 1995. "Notas de agricultura tradicional. El cultivo de los cereales en la Sierra Norte de Madrid. Etnografía Española 9: 99-123.

- 1996. Tecnología agrícola medieval en España. Una relación entre la etnología y la arqueología a través de los aperos agrícolas. Madrid: Ministerio de Agricultura, Pesca y Alimentación.

- 1997. “La etnohistoria como complemento de la arqueología medieval. Útiles y técnicas agrícolas en Segovia en el siglo XIII". Estudios Segovianos XXXIX (96): 221274.

- e. p. Los origenes del yugo como divisa de Fernando el Católico. La presencia del yugo para tres animales en la iconografia. Zaragoza: Institución Fernando el Católico.

MUÑOZ GORDO, A. 1994. Un museo rural. Segovia: Caja de Ahorros de Segovia.

RuIz MonTEJO, I. 1995. "La vida", en J. M. JOVER ZAMORA (dir.), Historia de España. XI. La cultura del románico. Siglos XI al XIII. Madrid: Espasa-Calpe.

- 1998. "La vida campesina en el siglo XII a través de los calendarios agrícolas", en Vida cotidiana en la España Medieval. Actas del VI Curso de Cultura Medieval: 107123. Madrid: Fundación Santa María la Real y Ed. Polifemo.

SÁNCHEZ GÓMEZ, L. A. 1991. Sayago. Ganadería y comunalismo agropastoril. Zamora: Caja España.

- 1993. Las debesas de Sayago. Explotación, trabajo y estructura social. Zamora: Caja España.

SERrano, L. 1910. Becerro Gótico de Cardeña. Valladolid. 
Tejado Ceña, J. M. 1993. Rastros. Etnografía de la Sierra. Logroño.

VIOlANT y SimORRA, R. 1949. El Pirineo español. Madrid: Plus Ultra.

- 1958. "El arado y el yugo tradicionales en Cataluña", RDTP XIV (3 y 4): 306-353 y 441-497.

YARZa Luaces, J. 1993. Los Reyes Católicos. Paisaje artístico de una monarquía. Madrid: Nerea. 